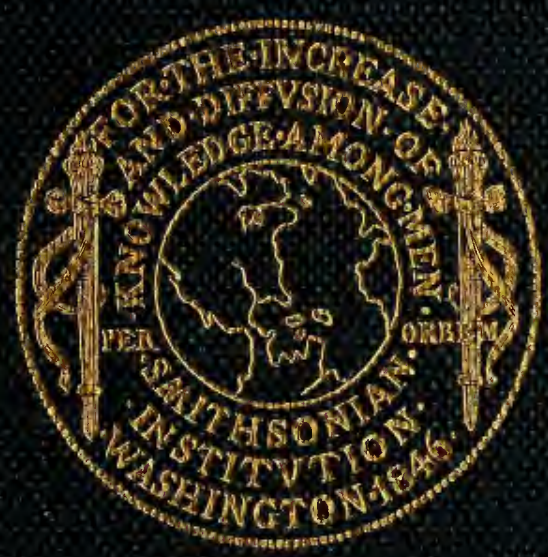

SMUTHSONLAN LIBRARY 



S M I THSONIA N I N S T I T U T I O N WA R B A C K G ROU N D S T U D I E S N U M B E R T E N

\title{
POISONOUS REPTILES OF THE WORLD: A WARTIME HANDBOOK
}

\author{
By \\ DORIS M. COCHRAN
}

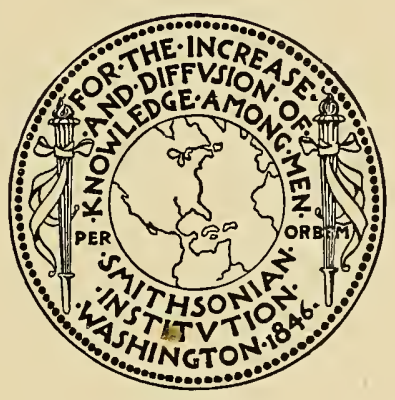

(Publication 3727)

CITY OF WASHINGTON

PUBLISHED BY THE SMITHSONLAN INSTITUTION

MARCH 19, 1943 


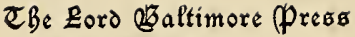
BALTIMORE, MD,, . S. A. 


\section{CONTENTS}

Introduction

Poisonous reptiles of the New World..................... 2

The United States of America..................... 2

The coral snakes........................ 3

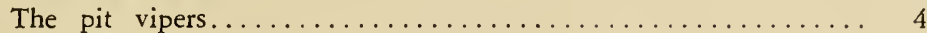

The timber rattler.................... 7

The diamondback rattler................... y

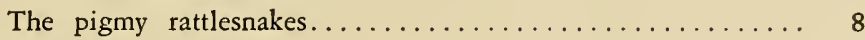

The water moccasin.................... 8

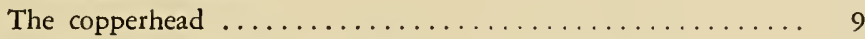

Distribution of our poisonous snakes ............... 9

The Gila monster...................... 10

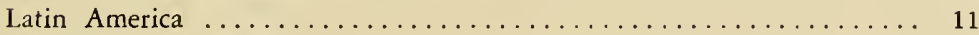

The coral snakes........................ 11

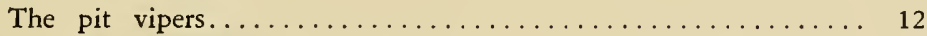

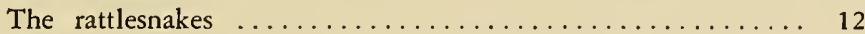

The cantil ............................ 12

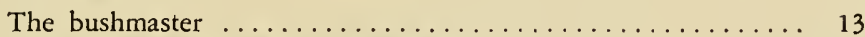

The fer-de-lance or barba amarilla............... 13

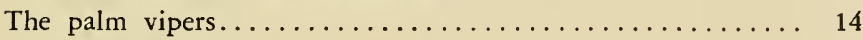

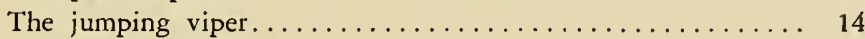

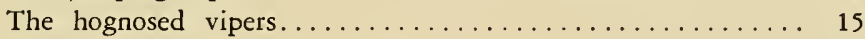

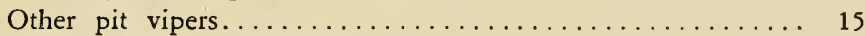

The semipoisonous tree snakes................... 16

The yellow-bellied sea snake.................... 16

The Mexican beaded lizard......................... 16

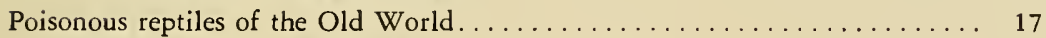

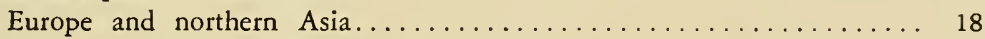

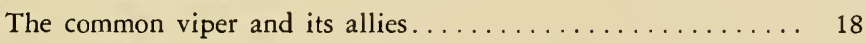

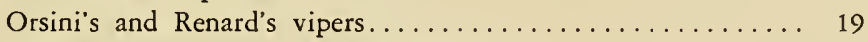

The asp, Lataste's and the long-nosed vipers............ 19

The blunt-nosed viper and its allies.............. 20

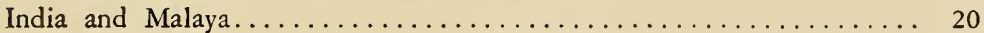

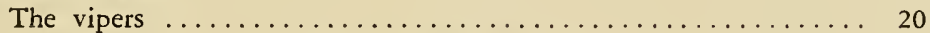

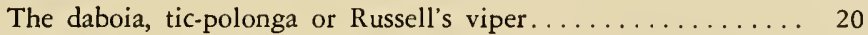

The carpet or saw-scaled viper................ 21

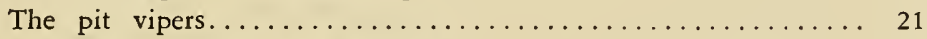

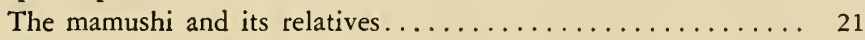

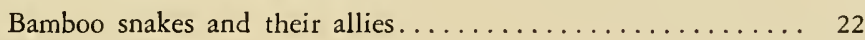

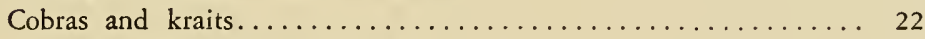

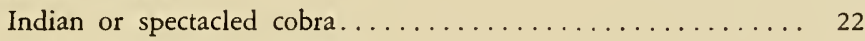

The king cobra or hamadryad.................. 23

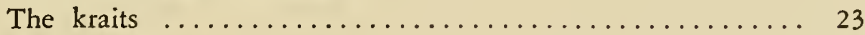

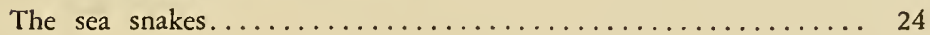




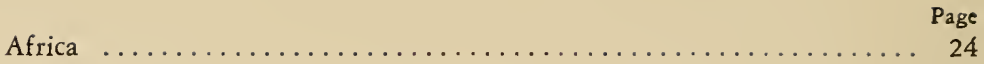

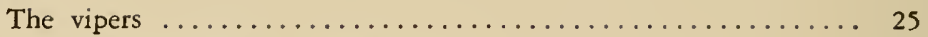

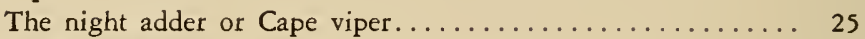

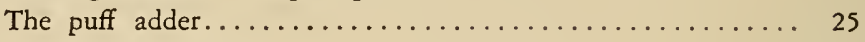

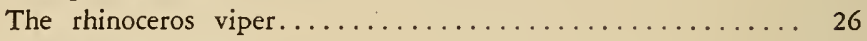

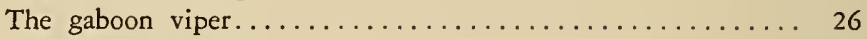

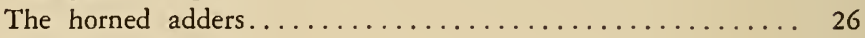

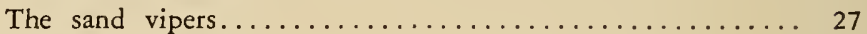

The cobras and their allies......................... 27

The ringhals or spitting snake................ 28

The spitting or black-necked cobra.............. 28

The black cobra.......................... 29

The Egyptian cobra or asp............................ 29

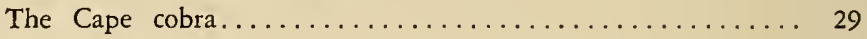

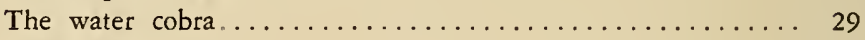

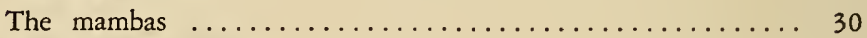

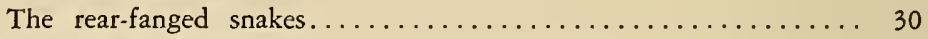

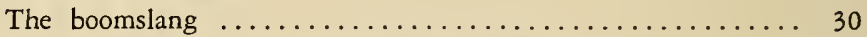

Australia, New Guinea, and the South Pacific islands.......... 31

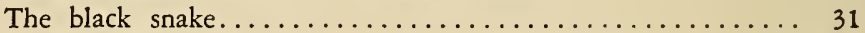

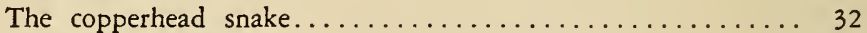

The brown snake...................... 32

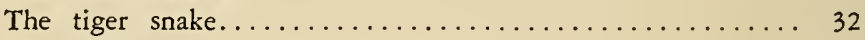

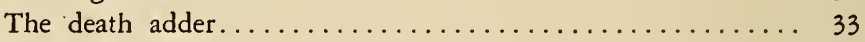

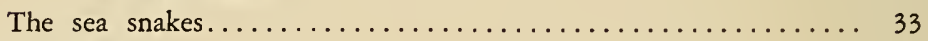

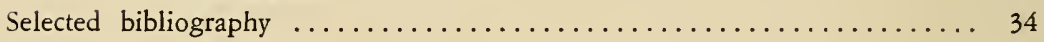

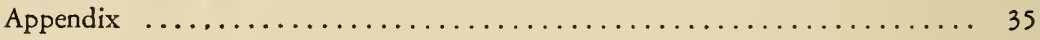

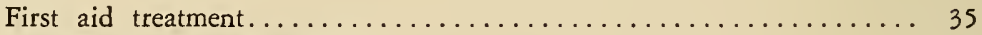

Antivenin and its preparation......................... 35

Directions for making scientific collections................ 36

\section{ILLUSTRATIONS}

\section{PLATES}

Page

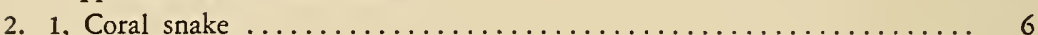

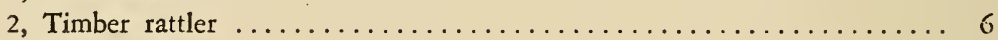

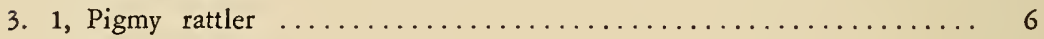

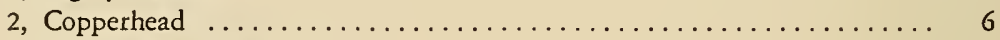

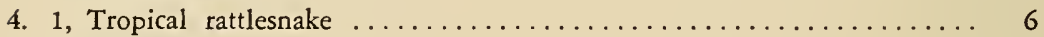

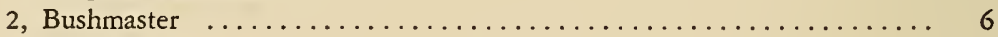

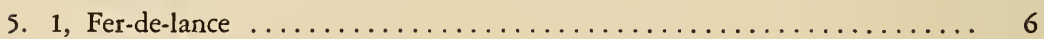

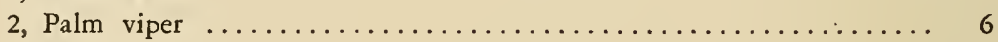

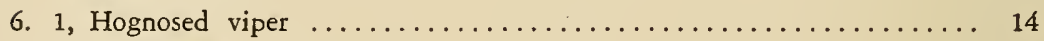

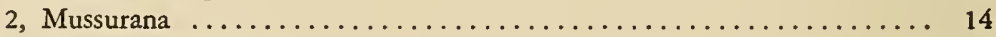

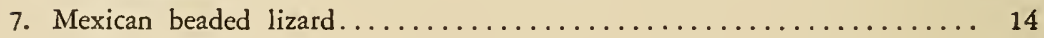


8. 1, Common Page

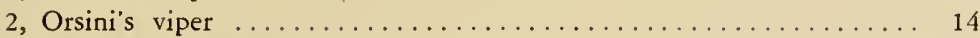

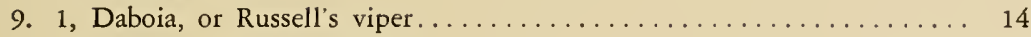

2, Indian or spectacled cobra....................... 14

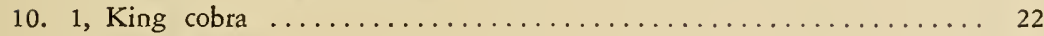

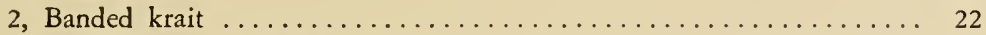

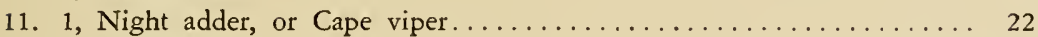

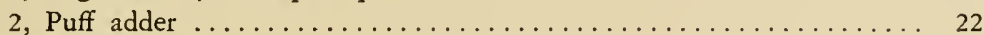

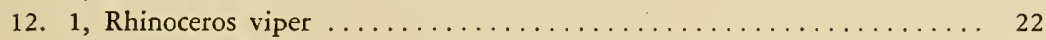

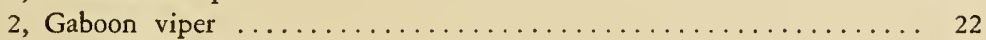

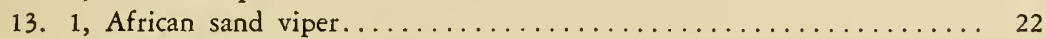

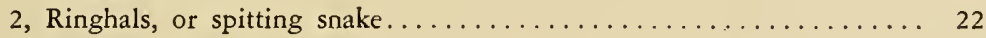

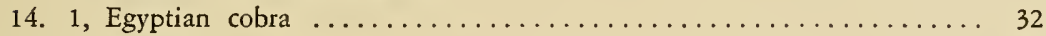

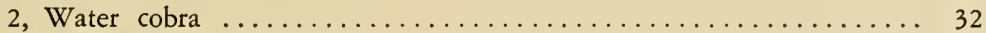

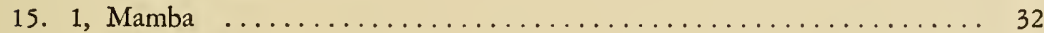

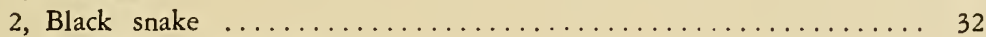

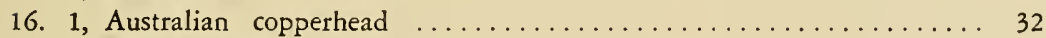

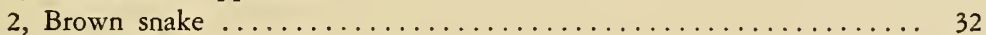

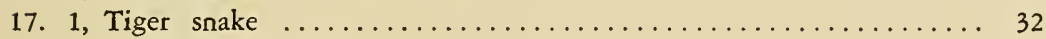

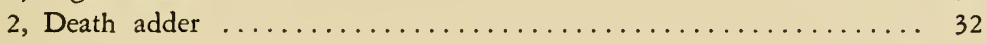

TEXT FIGURES

2. Yellow-bellied sea snake.......................... 17 




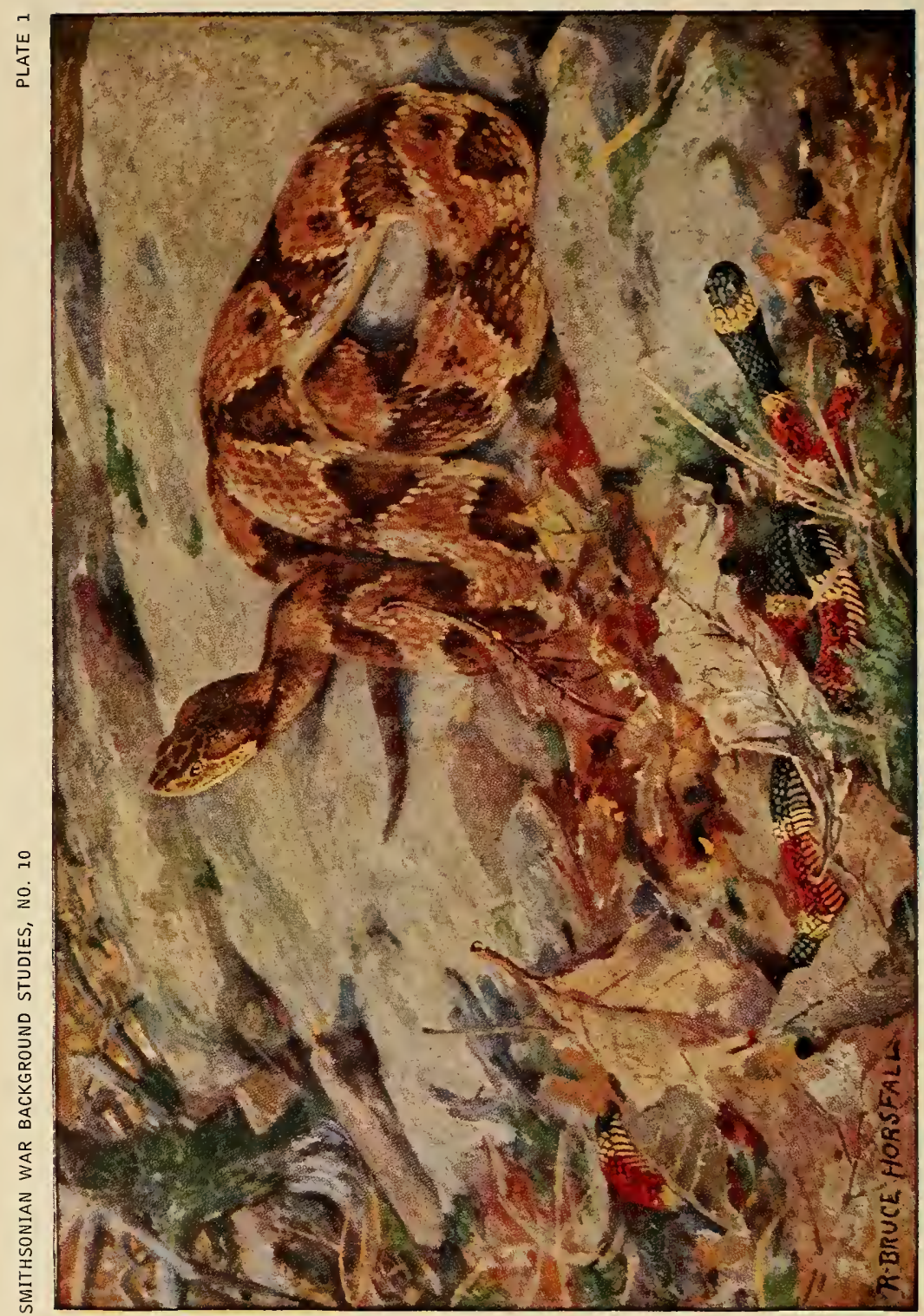

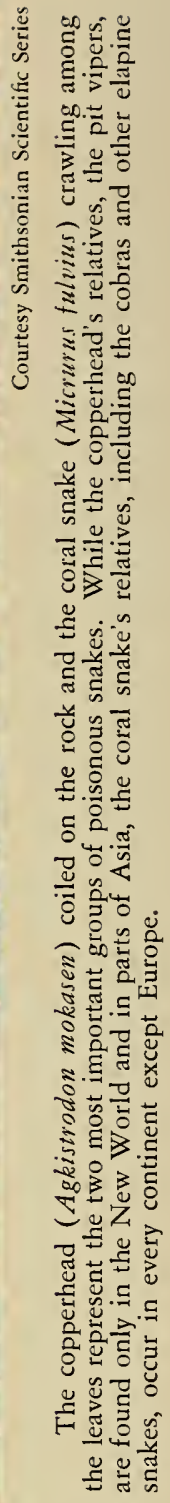




\title{
POISONOUS REPTILES OF THE WORLD: A WARTIME HANDBOOK
}

\author{
BY DORIS M. COCHRAN \\ Associate Curator, Division of Reptiles and Batracbians \\ U. S. National Museum
}

(With 17 Plates)

\section{INTRODUCTION}

Among a world population of some 2,400 different kinds of living snakes, less than 200 are dangerous to man. These are unequally distributed among four families-the Elapidae; the Viperidae; the Crotalidae, of which every member is poisonous to a varying degree; and the Colubridae, which contains nearly two-thirds of the known species of snakes but consists mostly of harmless kinds, the only dangerous ones being some of the rear-fanged snakes. The Hydridae and the Amblycephalidae, the remaining families of poisonous snakes, are so unobtrusive in their habits that they rarely conflict with man. Some poisonous snakes are extremely useful in destroying rats and mice, but this desirable trait is offset near inhabited districts by their occasional biting of human beings or domestic animals.

The chances of being bitten by poisonous snakes are exceedingly small. Only about one-sixth of our native snakes are poisonous. One person out of every fifteen bitten receives the bite while handling or "playing" with a poisonous snake. "In the United States alone automobiles kill more than 30,000 people annually, snakes probably 160 ; for every person killed by a snake, 200 die in automobile accidents." 1 This does not mean that vigilance should be relaxed in traveling through snake country. On the contrary, it is well to recognize the presence of a very real danger as the best means of avoiding it.

The distribution of poisonous snakes throughout the world is now fairly well known. They do not live in the extremely cold regions of any country; thus in North America they are known only as far north as the southern borders of Canada. Since the continents to the south of the Equator lie much farther from the Poles than do those to the north, we find poisonous snakes over the whole of Africa and in most of South

1 Pope, Clifford, Snakes alive, p. 171, 1937. 
America, except on the high mountains and in southern Patagonia. An extremely hardy viper occurs in Scandinavia to within the Arctic Circle; this is the record for cold endurance among the venomous snakes. The Polynesian islands are free of land-dwelling poisonous snakes. So are Madagascar and New Zealand, although both of them are relatively close to areas where many very dangerous kinds prevail. The Azores, and the Canary and Cape Verde Islands near Africa, have none. The large and small islands of the West Indies lack poisonous snakes, except Trinidad, Tobago, Martinique, and St. Lucia. In the Temperate Zone their absence from Ireland has often been noted. They are also missing from Iceland, the Shetlands, and the Orkneys.

The true vipers (family Viperidae) are found only in the Old World, and the dangerous rear-fanged colubrids are practically confined to Africa. The crotalids are found in the New World and in Asia, while the elapids occur in all the continents except Europe.

Snakes and lizards are both members of the same order-Squamata-in the class of reptiles. The other living members of this class-turtles and crocodilians-are not equipped with venom glands.

Only two kinds of lizards out of nearly 3,000 now known to science have proved to be poisonous, with one other very rare species suspected to be so. The two poisonous lizards live in the southwestern United States and Mexico. The one suspected of being poisonous occurs in Borneo.

\section{POISONOUS REPTILES OF THE NEW WORLD}

\section{THE UNITED STATES OF AMERICA}

Every one of our 48 States has at least one kind of poisonous snake living within its boundaries. All except the most northerly have several kinds. The Gila monster, our only poisonous lizard, brings to nearly 40 the total number of kinds of poisonous reptiles in our country.

The poisonous snakes of the United States belong to two major groups: the Elapidae, represented by coral snakes, which are related to the cobras of Asia and Africa, and the Crotalidae or pit vipers, represented by the true rattlesnakes, the pigmy rattlers, the massasauga, the copperhead, and the cottonmouth.

The venoms of the different species of poisonous snakes differ to a greater or less degree. All venoms contain several toxins which act independently of each other, the most important of which are the hemorrhagins and the neurotoxins. The hemorrhagins constitute the chief toxic elements of the venom of rattlesnakes and most of the other pit vipers. 
This type of poison dissolves the endothelial cells composing the walls of the blood and lymph vessels, especially of the capillaries. The neurotoxins, which characterize the venom of the coral snake and its relative the cobra, have a destructive action upon the nervous system and play the most important part in producing the death of a victim of snake bite. This toxin breaks down the nuclei of the ganglion cells and produces granular disintegration of the myelin sheath and fragmentation of the conducting portions of the nerve fibers. The two poisons are almost as diagnostic of the two snake families as the structural differences of their poison apparatus.

\section{The Coral SNakes}

The first group, family Elapidae, is very similar in build to most harmless snakes. The poison apparatus consists of short, vertical fangs requiring a full bite for the injection of the poison. There is no very conspicuous enlargement at the base of the jaws to give a triangular shape to the head supposedly characteristic of poisonous species.

It has been repeatedly asserted that the mouth [of the coral snake] is so small that it can not bite as well as the other poisonous snakes. This, however, is somewhat of a mistake. Externally and superficially the head .... appears very short and narrow, and the opening of the gape but of slight capacity. An examination of the skeleton, however, shows the skull to be comparatively large and rather elongate, especially the cranial part, which occupies fully two-thirds of the total length of the head. The articulation of the lower jaw, which is correspondingly lengthened, is consequently far enough back to permit, by means of the elasticity of the ligaments, the opening of the mouth quite out of proportion to the external aspect of the snake. ${ }^{2}$

Since the coral snake is often sluggish and "gentle" when handled, some persons have said that it can hardly be induced to bite. It sometimes will bite very suddenly and unexpectedly, however, but as the wound appears small and unimportant, the necessary treatment is often neglected, with serious results to the victim because of the highly toxic character of its poison.

The coral snake is attractively colored with bright red, yellow, and black transverse rings on its body (pl. 1, frontispiece, and pl. 2, fig. 1). The snout from the eyes forward is black, thus differing from two harmless snakes which mimic its pattern, but which have pinkish or yellowish noses. If in killing the snake the pattern of the head is lost, the coral snake may be identified by its black rings being bordered on each side by a

2 Stejneger, L., Poisonous snakes of North America. Ann. Rep. U. S. Nat. Mus. for 1893 , p. 355, 1895. 
yellow ring, while in the harmless species it is the yellowish ring which is bordered on each side by a black ring. There are two different species of coral snakes found in this country, one species occurring from North Carolina through the Gulf States, north along the Mississippi to Ohio and Indiana, with a local form in southern Florida, the other in southern New Mexico and Arizona. Our North American kinds seldom exceed 3 feet in length, but numerous larger relatives are found in South and Central America, where they are a recognized menace. Our species feed upon other snakes and small lizards. They burrow in soft ground or under logs and are hence seen more infrequently than their actual numbers warrant. They come out of their burrows at night or after a rain to search for food. Their eggs are deposited in decaying bark or damp soil, about seven in a clutch. The time of incubation, in this as in all other egg-laying snake species, depends upon the heat and moisture; it is usually about 3 months.

\section{The PIT Vipers}

The pit vipers, so called because of the small pit between the nostril and the eye, representing the Crotalidae, are much more numerous than the Elapidae since no less than 35 different species and subspecies are recognized within the United States. The rattlesnakes need no introduction, for they are known by reputation, if not by actual contact, to everyone in this country. The presence of a whirring rattle on the tail tip is their spectacular and distinguishing characteristic. The rattlesnakes are divided among two genera, Crotalus and Sistrurus, the first having many small scales on top of the head, the second with several large regular shields in that region. To the genus Sistrurus belong the massasauga and the pigmy rattlesnakes, whose venoms are less to be feared because of their small size.

Venom and bite.-While we usually speak of the "bite" of a pit viper, it is much more accurate to refer to it as a strike. The snake strikes usually from an S-shaped position, the posterior third of the body remaining on the ground to give necessary leverage for the blow. Hence two-thirds of the body length is the maximum striking distance. None of our North American pit vipers actually jumps off the ground in making an attack. As the head is thrown forward for the blow, the mouth is opened, and the fangs, which are attached solidly to the movable maxilla, are brought into striking position as shown in figure 1 . The venom is contained in a large specialized salivary gland at the angle of the jaw (its presence is the cause of the conspicuous triangular widening of the snake's head pos- 

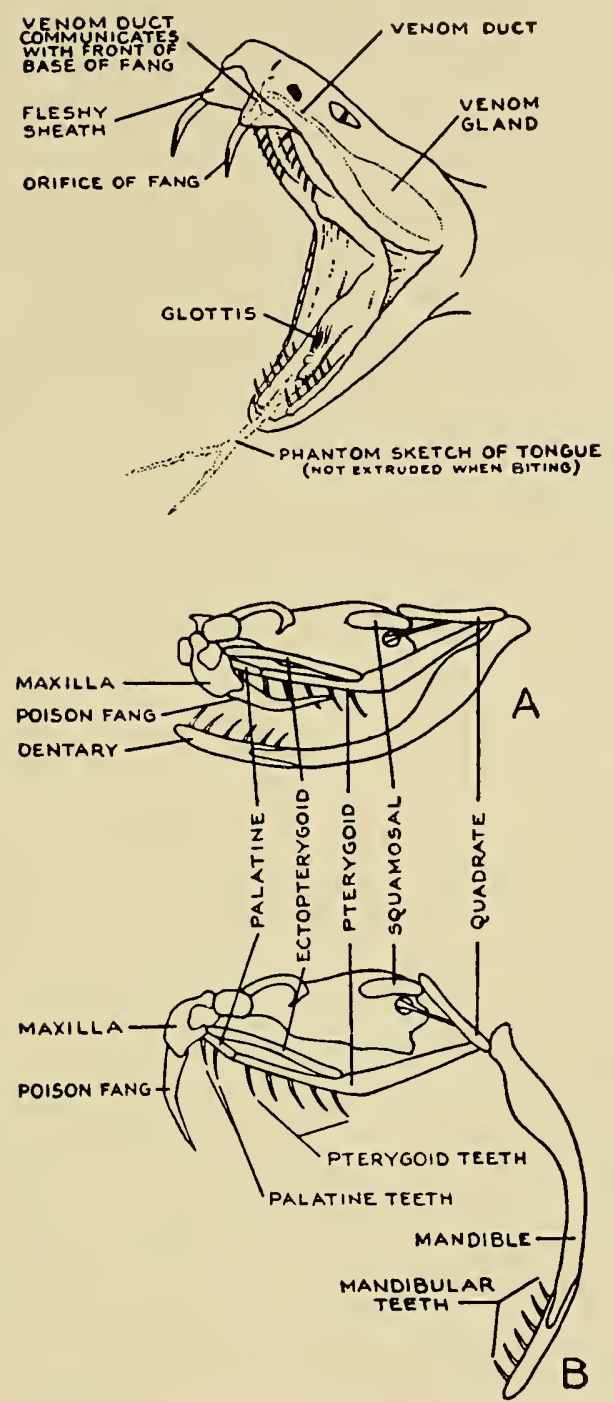

FIG. 1.-Upper, diagram of venom apparatus of rattlesnake. Lower, diagram of bones involved in biting mechanism of rattlesnake: A, jaws closed, fang folded back against roof of mouth; B, jaws open and fang erected for biting. (From The reptiles of Ontario, by E. B. S. Logier, 1939.) 
teriorly), and this venom runs forward through a tube connecting with the hollow fang in the upper jaw. The comparison to a hypodermic needle is very appropriate. When the snake's fangs strike the victim's flesh, the weight of its body drives them deep, and they leave their load of venom or are sometimes broken off and stay in the wound. The loss of its functional fangs does not long inconvenience the pit viper, however. There is a series of small developing teeth at the base of each fang, and whenever a fang is shed or breaks off, a new one comes forward to take its place in a few days. To render a pit viper "harmless" by removing all these fangs thoroughly would necessitate cutting into the upper jaw so deeply that the snake would probably die. Every pit viper has also some solid teeth with which to hold the prey and prevent it from wriggling away while the snake is attempting to swallow it. The amount of venom delivered at one strike varies greatly even in the same individual. If the snake is in poor condition, if it has already struck recently, or if the fangs have to penetrate layers of hide, fur, and fat-or in the case of human beings, clothing or shoes-the amount of poison that is injected is correspondingly less than normal. The diamondback rattler of the southeastern United States is our largest species and hence has probably the longest fangs-about $\frac{3}{4}$ inch in a 6 -foot snake. The fangs at rest are covered by whitish folds of skin, in the cottonmouth very apparent when the snake opens its mouth.

Additional facts about pit vipers.-It is a popular but erroneous belief that a rattler's age is told by counting the rings in its rattle. The fact is that a ring is formed every time the growing snake sheds its skin; hence a young snake acquires three or four rings during its first year of life, and about as many more each year during its later years. By the time it has reached nearly maximum growth, it often accidentally breaks off most of its rattle-which is composed merely of rings of dried, hornlike skinso that a very large snake presumably several years old may have only one or two rings. Circus men overcome that difficulty by fitting several rattles onto a big snake's tail to make it more imposing to the trusting audience.

The colors of most pit vipers are much duller than those of the brilliant coral snake previously discussed. Rattlers especially are inclined to dull, dark tones as they reach adulthood, and this effect is increased by the keels on the lusterless scales which further roughen their skins. A diamond or chevron in brown or gray on a light tan ground is often the basis of the color pattern. The diamondback has an unusually distinct diamond design; hence its name.

The pit vipers are so named from the presence of a small pit in the side of the head between the eye and nostril. This pit is filled with sensory 


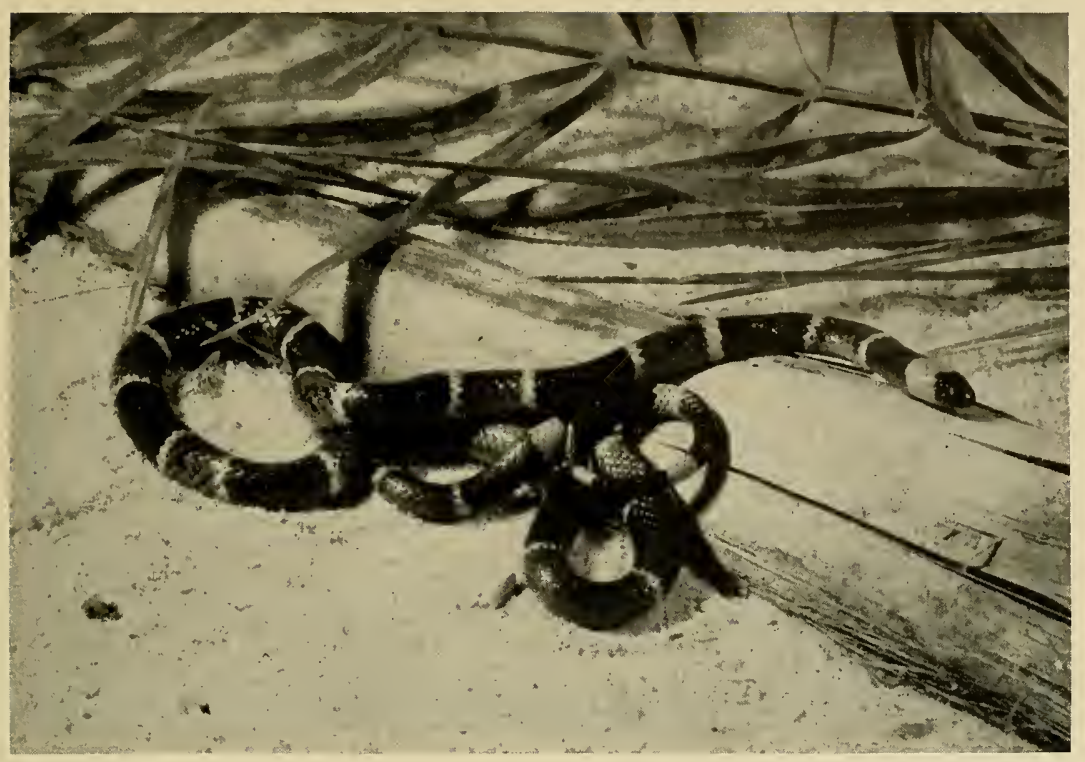

Courtesy Philadelphia Zoological Society

1. Coral snake (Micrurus fulvius), also called harlequin or bead snake. Color: wide rings of crimson and black, the latter narrowly bordered with yellow (see frontispiece). Length: 3 feet. Range: North Carolina to Florida; the Gulf States and Mississippi Valley States north to Ohio and Indiana.

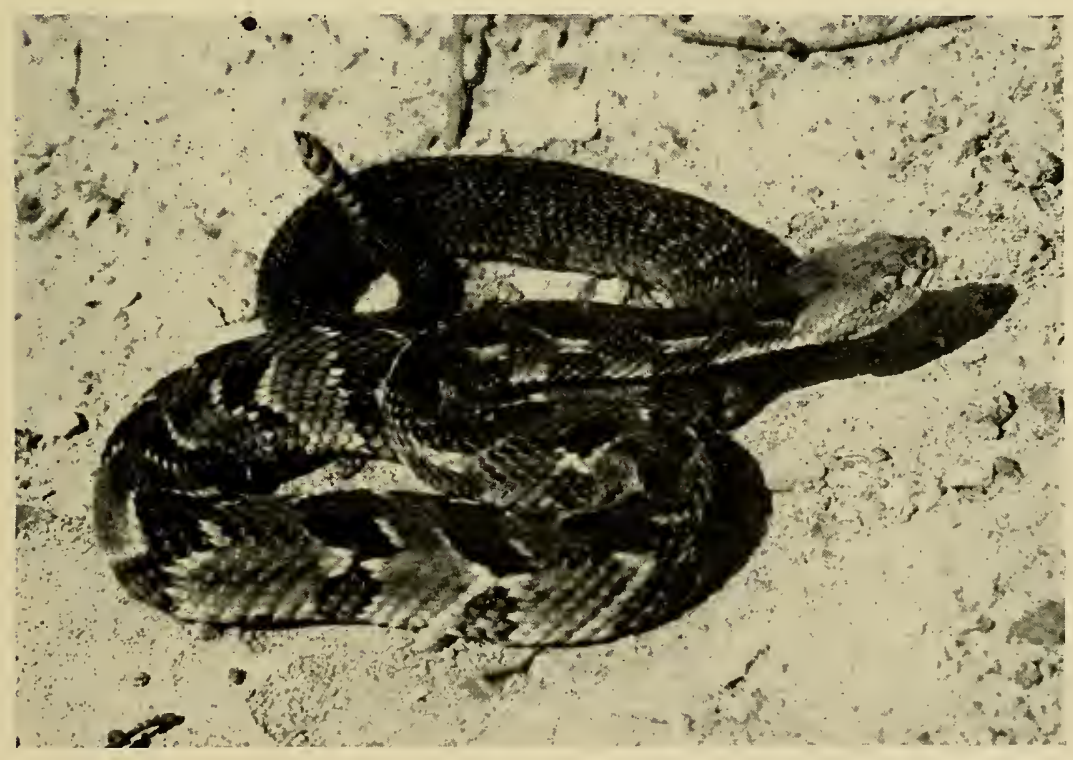

Courtesy Philadelphia Zoological Society

2. Timber rattlesnake (Crotalus borridus), also called black or banded rattler. Color: yellow or tan, with wavy cross bands of dark brown or black, sometimes almost entirely black. Length: $5 \frac{1}{2}$ feet. Range: Maine to Georgia, west through Louisiana to Texas; the Mississippi Valley States into Wisconsin. Extremely poisonous; aggressive if disturbed. 


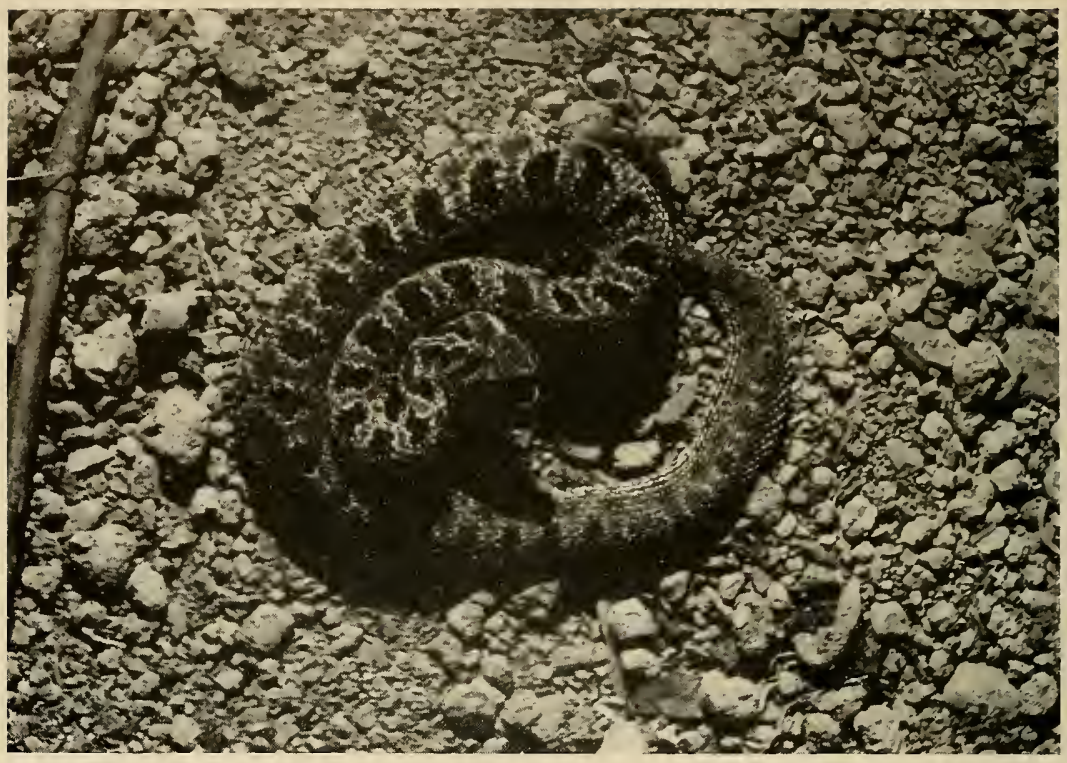

Courtesy Dr. W. Gardner Lynn

1. Carolina pigmy rattler (Sistrurus miliarius), also called ground rattler. Color: grayish with a series of darker rounded blotches and a reddish band along the back. Length: 20 inches. Range: North Carolina to Georgia and Alabama.

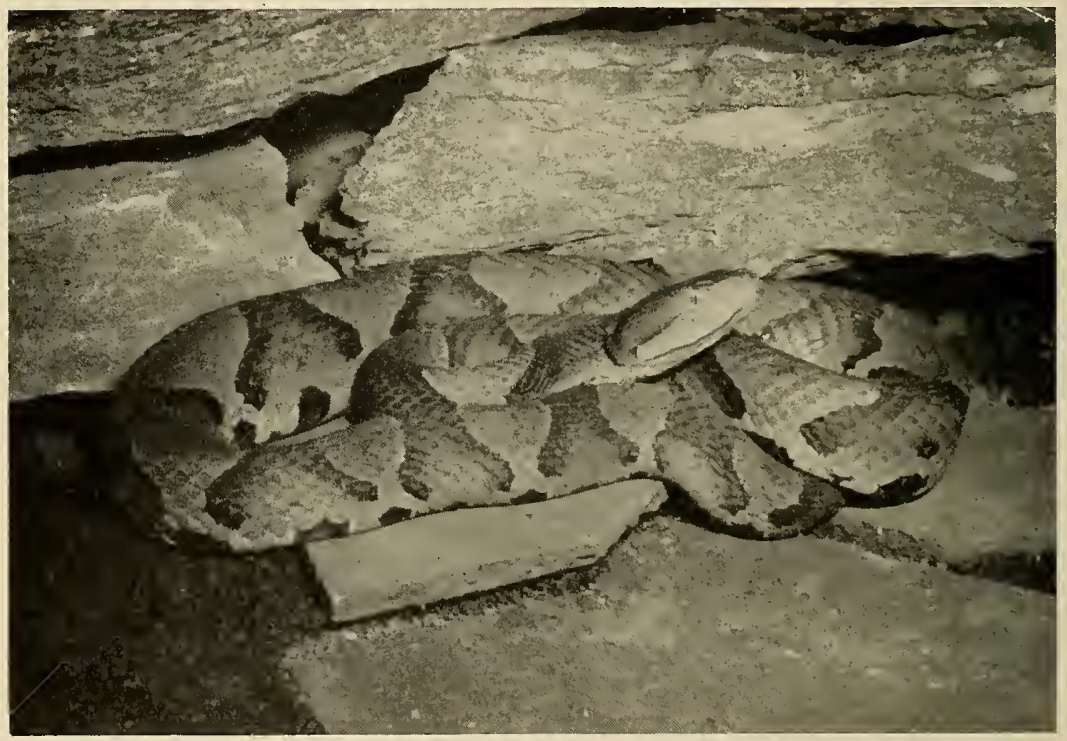

Courtesy Philadelphia Zoological Society

2. Copperhead (Agkistrodon mokasen), also called rattlesnake pilot, chunk-head and highland moccasin. Color: pale brown, pinkish or light reddish brown, with a series of chestnut-brown hour-glass-shaped markings (see frontispiece). Length: 4 feet. Range: Massachusetts to Georgia and the Carolinas, exclusive of peninsular Florida. Not aggressive unless disturbed. 


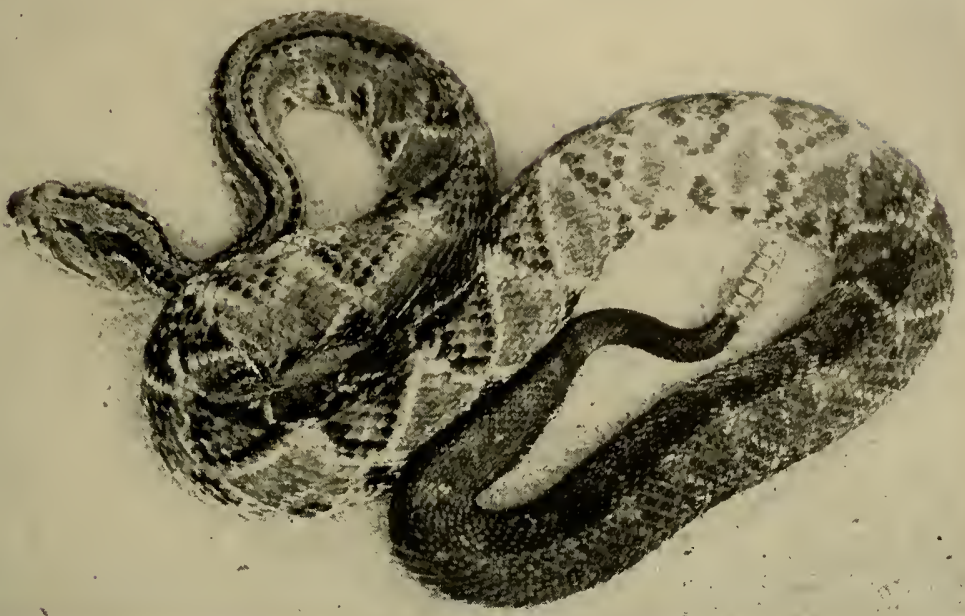

Courtesy Bulletin of the Antivenin Institute

1. Tropical rattlesnake (Crotalus terrificus), also called cascabel. Color: yellowish gray with large dark brown "diamonds" on the body, and a pair of dark longitudinal stripes on the neck. Length: 6 to 7 feet. Range: drier parts of the Guianas, Venezuela and Colombia to northern Argentina, Paraguay and southern Brazil. Most poisonous of all the rattlers; very aggressive.

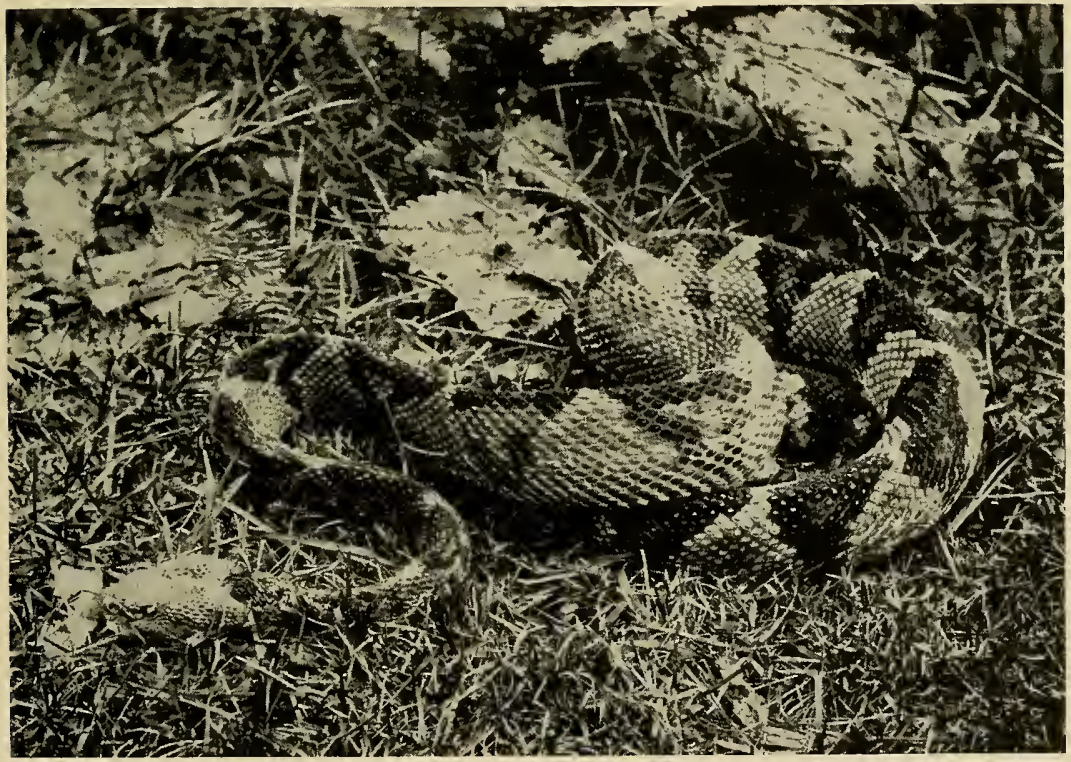

Courtesy New York Zoological Society

2. Bushmaster (Lachesis mutus), also called la cascabela muda in Central America, surucucu in Brazil, and mapepire z'ananna in Trinidad. Color: pale brown, often pinkish, with a series of large brown blotches wider on the back and abruptly narrower on the sides. Length: over 11 feet. Range: southern Central America through tropical South America, including Trinidad. Exceedingly poisonous; aggressive. 


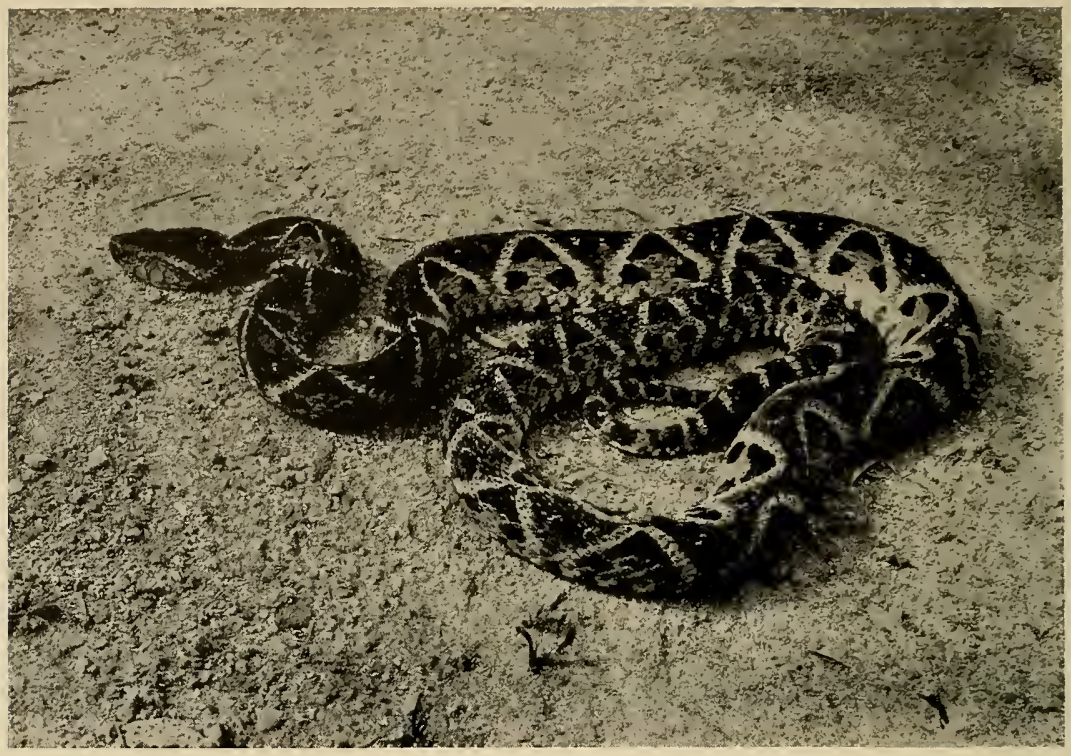

Courtesy New York Zoological Society

1. Fer-de-lance (Botbrops atrox), also called barba amarilla, jararaca, terciopelo or tomigoff. Color: gray to olive, brown or reddish, with dark, light-edged cross bands or triangles, the apex of these extending to the center of the back. Length: 8 feet. Range: southern Mexico to central Brazil, also Trinidad and Tobago; Martinique and St. Lucia in the West Indies. Exceedingly poisonous.

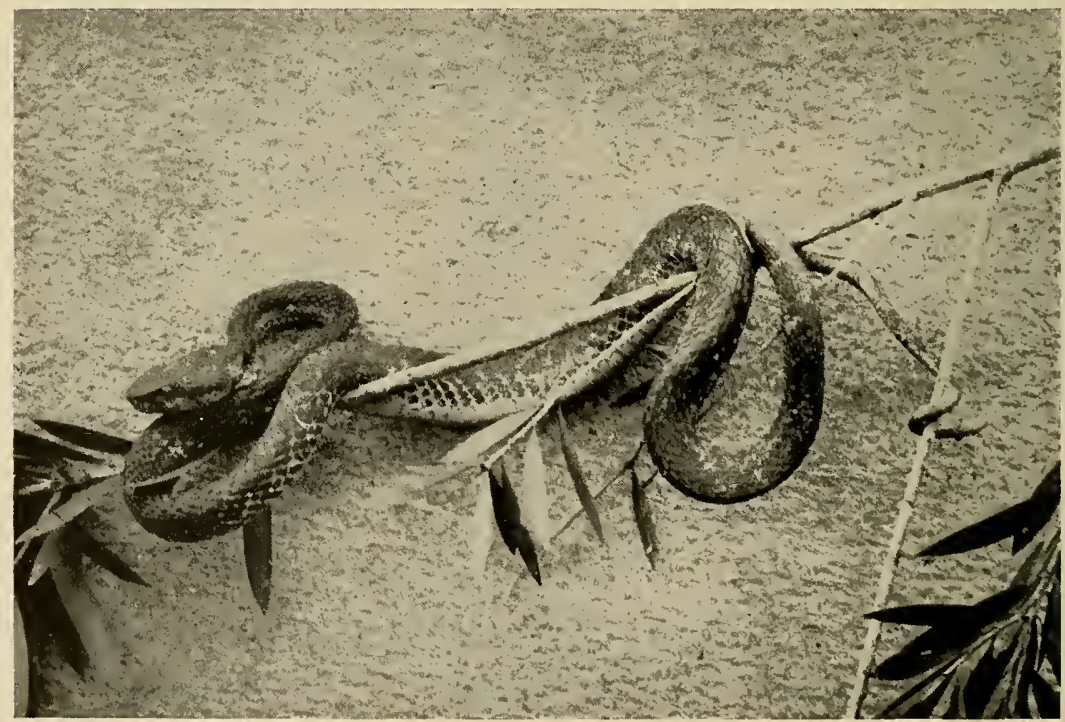

Courtesy Nature Magazine

2. March's palm viper (Bothrops nigroviridis marchi). Color: uniformly brilliant green above, merging into yellowish green on the sides. Length: not quite 2 feet. Range: Honduras. Dangerously poisonous. 
cells the function of which is still somewhat in doubt. It is believed from experiment that the cells in the pit enable the snake to distinguish between cold and warm air currents and hence to know when some warmblooded animal approaches it in the dark-a useful function since most pit vipers are nocturnal and do their hunting at night. Their food consists of anything small enough to be swallowed-birds, mammals, sometimes fish, frogs, snakes, lizards, or small turtles-each species showing a "preference" for some of the food items that it normally can obtain in its own particular environment.

Most pit vipers are viviparous - that is, their young are born, instead of being hatched from eggs as is the case with the coral snakes. Young snakes begin to look for food very soon after birth. Their skin is shed within a few days for the first time.

\section{The timber rattler}

First of the more common species on the list for easterners is the timber rattlesnake (Crotalus horridus, pl. 2, fig. 2), also called the banded or black rattler.

Distribution of this rattlesnake in the northeastern states is associated with hills and mountains of moderate height, on which there are broken ledges with large, loose fragments on the slopes and top. These flat fragments may be a foot or more in thickness and from a yard to six or eight feet in length, sloping back into a fissure, the bottom of which may be covered with soil or leaves, and which provides a position of security during storms. It is the common habit of rattlesnakes to coil under the edge of these rock masses, protected from the too hot summer sun, and ready to quickly retreat if disturbed. If the intruder goes on his way, the snake may lie in its motionless coil, without sounding the rattle, thus seeking to escape notice. Near these natural homes are specific crevices or "dens," where rattlers that have roamed over a considerable area during the summer congregate each fall preparatory to deep penetration and hibernation, beyond the frost line. During the late summer the females return to such places and here the young are born, with a natural instinct to return to this specific area each year for winter shelter. . . . . ${ }^{3}$

\section{The diamondback rattler}

The diamondback rattlesnake (Crotalus adamanteus), already mentioned, lives in wooded areas of the Southeast, especially among the scrub palmetto of the sea beaches in Florida. "It is not a swamp species, although it may frequent woods close to water and does not hesitate to swim across small bodies of water. In the coastal strips it crosses fair-

${ }^{3}$ Ditmars, R. L., Snakes of the world, pp. 114-115, 1934. 
sized tide pools and has been noted several miles from shore, where it has been accidentally carried by the currents. It is also found among the keys. When adult, its food consists largely of rabbits," ${ }^{4}$ and sometimes of quails. There is a western diamondback which is said to cause twice as many deaths as the eastern species. The prairie rattlesnake and the water moccasin make up the other species which together with the diamondback are responsible for about 95 percent of deaths by snake bite in this country.

\section{The pigmy rattlesnakes}

"The bites of pigmy rattlers and massasaugas (genus Sistrurus) are practically never fatal to adults, except possibly through septic combinations. These rattlers are our least poisonous snakes, for of 20 cases on record, none ended fatally." 5 They frequently feed upon frogs, which is contrary to the habits of the main rattlesnake genus (Crotalus), the members of which, at least when fairly grown, or when mature, seem to feed exclusively upon warm-blooded animals - mammals and birds. The massasauga is about $3 \frac{1}{2}$ feet long. It frequents swampy places, although it shuns the actually wet places. It is brownish or grayish, with chestnutbrown blotches on the back and a similar row on each side. The ground rattler (pl. 3, fig. 1) is seldom more than 20 inches long, with a very minute rattle. It prefers dry areas with low vegetation. Its venom is particularly powerful, but the small amount of it injected at a bite is not known to have been lethal to man.

\section{The water moccasin}

While the rattling of the rattlesnake is said to be a warning device, there are many pit vipers which have no rattle and hence cannot give the warning. Perhaps the most dangerous of these in the confines of the United States is the water moccasin (Agkistrodon piscivorus), or cottonmouth. Adults are dull olive or brownish above and paler on the sides, on which are indistinct blackish bands. Young specimens are brilliantly colored, usually of a pale reddish brown with bands of dark brown narrowly edged with white. The snake is one or the largest of the poisonous ones in this country, attaining a length of 6 feet, and it is also one of the most pugnacious in its wild state. Over most of its distribution it lives along streams and lakes or in swamps and is particularly abundant along aban-

\footnotetext{
4 Idem, pp. 113.

5 [Kellogg, R.], Poisonous snakes of the United States. Mimeographed circular Bi-571, U. S. Dep. Agr., Bur. Biol. Surv., February 1925.
} 
doned rice ditches of the southeasterly and Gulf States. In captivity it feeds upon small rabbits, rats, birds, fishes, and frogs.

\section{The copperhead}

Another rattleless pit viper is the copperhead (Agkistrolon mokasen, pl. 1, frontispiece, and pl. 3, fig. 2). It can be recognized by its reddishbrown hour-glass-shaped marks going over the back, set off by the light buff or reddish-tan ground color. A very large copperhead may be as much as $4 \mathrm{feet}$ long. It feeds upon small rodents, birds, and frogs. In the northern States it frequents rocky places, usually in the vicinity of moderately thick timber, marshy glades or hollows. In the South it is found on higher and drier ground than are the timber rattler and water moccasin, which seem to prefer the swamps. Baby copperheads, as well as the young of all other poisonous snakes, are venomous from the moment of birth. Although an adult copperhead secretes a relatively small amount of venom, a great many persons are bitten owing to the snake's concealing coloration, which blends perfectly with the ground covered with fallen leaves. A number of harmless snakes are similar in appearance to the copperhead and are often confused with it. Several species of the watersnake (Natrix) are characterized by brown markings on the back somewhat like the pattern of the copperhead. The inside of a watersnake's mouth is white, and its habit of opening the mouth at its aggressor is a terrifying action, although it has no poison fangs. It is savage in disposition and its lacerating bite from the many short, solid teeth may lead to an infection if not thoroughly disinfected. The hognosed snake (Heterodon), also called puff adder and upland moccasin, is likewise a very close mimic of the copperhead.

\section{Distribution of Our Poisonous Snakes}

The matter of distribution cannot be explained in a few words. Sometimes no poisonous snakes occur in what seem to be the most favorable localities. Again they will be found in some special habitat perhaps near a town or city where repeated attempts to exterminate them have been made. The more northerly the locality, the fewer the species as a rule. New England, for instance, has but two species, the copperhead and the timber rattler, and the former does not go north of central Massachusetts. The massasauga is added in the upper Mississippi. The canebrake, the Carolina pigmy, the diamondback, and the dusky pigmy complete the number of rattlesnakes in the southeast.

Crossing the Mississippi, we find a much more numerous assemblage. 
The western diamond, the red diamond, the Pacific, and the prairie are among the most formidable. The western massasauga and the western pigmy rattler, the Texas rock rattler, the tiger and the black-tailed rattler, the speckled and faded and Great Basin rattlers, and the Willard's, Price's, and green rock rattler occur through the west between Canada and the Mexican border. One of the most peculiar, though not particularly dangerous, is the little sidewinder, so called from his sinuous track left in the sand. He has "horns" on his head, as the scale about his eye is enlarged and bluntly pointed, although it is not stiff enough to cause any damage, nor is it known to be used in self-defense. To this list must be added two forms of the copperhead, and the water moccasin. Each of these snakes thus briefly mentioned deserves a much fuller discussion than can be accorded in a paper of this size.

The best advice in dealing with supposedly poisonous reptiles is to leave them alone if possible. It is not at all a wise policy to exterminate every snake in sight, since many harmless snakes are of actual economic value. The depredations of rats, mice, moles, and gophers are certainly controlled by the rodent-eating snakes, and such snakes even if poisonous should definitely be protected in any agricultural area.

\section{The Gila Monster}

The final poisonous reptile under consideration is the Gila monster (Heloderma suspectum) or beaded lizard, occurring from the southern part of Utah and Nevada through Arizona into Sonora, Mexico. This and a related species in Mexico are the only known poisonous lizards. The Gila monster is heavily built and may grow to 2 feet in length, of which over one-third consists of the rounded tail. The entire animal is covered with coarse beadilike scales, salmon-red and black in color and forming a very beautiful blotched pattern. The head is blunt and massive, and the rather small legs seem inadequate to support it. In the warm sun the lizard can become very active, however, and can move about with surprising agility. The clublike tail is a storage place for fat. When the lizard has been getting an abundance of food, the tail becomes swollen and heavy. In time of starvation, the tail shrinks decidedly, as the body of the lizard is nourished by the stored-up fat. The food consists of eggs of birds and reptiles and also probably any small animal that it can pick up. For a long while its ability to poison was doubted.

The first confirmation of its poisonous nature seemed to be established by the discovery of grooved teeth, about $3-4 \mathrm{~mm}$. long, four on either branch of both maxilla and mandibular. ... . The mandibular appears somewhat swollen, owing to the projection of its disproportionately large, elongated submaxillary glands, 
whose four separate ducts lead to the base of the above-described grooved teeth. .... The arrangement of the teeth and of the glands makes us understand why opinions as to the poisonous nature of heloderma have differed so widely. When an animal seizes its victim only with the front teeth, or does not lie on its back while biting, none or very little of the buccal secretion may enter the wound. . . . .6 The Gila monster is known to turn over on its back when it is biting, and after it has once taken hold it chews on the wound.

\section{LATIN AMERICA}

While most tropical countries are abundantly supplied with poisonous snakes, it is a surprising fact that they are totally absent on nearly all the large and small islands that make up the West Indies. On Trinidad and Tobago, allied faunistically as well as geographically to the mainland of South America, we find the bushmaster, a typically South American species, and the coral snake. On Martinique and St. Lucia the fer-de-lance, a close relative of the bushmaster, likewise occurs. The mongoose was brought from India and introduced upon Martinique and Trinidad to kill snakes, but has proved to be a pest in many instances where it turned to the destruction of fowl and other useful birds instead.

Since many of the tropical poisonous snakes of this hemisphere range over both Central and South America, these species will be considered first, with the more important of the localized forms which are confined to a smaller area considered at the end of this section.

\section{The Coral SNakes}

Like their relatives of the United States, the tropical coral snakes (genus Micrurus) are burrowing and secretive in their habits. Their brilliant coloring of red, yellow, and black bands makes them easy to detect among the vegetation. Some nonvenomous snakes mimic their coloring closely. Their bright pattern, much alike in all the species, has given them the common name of coralilla in Mexico, and of gargantilla (=necklace) in Central America. While they are not aggressive if undisturbed, they will bite when stepped on or handled roughly. The larger kinds can inject a lethal dose of poison; the wearing of canvas leggings and leather shoes provides adequate protection against coral snake bite when traveling in "snake country," as their fangs are not long.

Two of the commonest South American coral snakes are Micrurus frontalis, found in southern Brazil to the Argentine, and Micrurus lemniscatus, occurring in the Guianas and Brazil. While these may appear "gentle,"

${ }^{6}$ Ditmars, R. L., The reptile book, p. 170, 1907. 
they will treacherously turn and bite if they are carelessly handled. A length of 4 feet is fairly common, with a corresponding volume of venom produced at a bite, and they should be regarded as highly dangerous.

\section{THE PIT VIPERS}

\section{The rattlesnakes}

The rattlesnakes (genus Crotalus) with which we have become so familiar in the United States have many close relatives in the lands to the south. The habits of these tropical rattlers are much like those of the rattlesnakes of our own country. Some of the species are very rare, only three or four ever having been found by naturalists even after the most assiduous collecting. Some are very small, and hence unable because of their short fangs to inject a lethal amount of poison. One of the larger kinds, Crotalus terrificus (pl. 4, fig. 1), is the only member of the genus in South America east of the Andes, ranging from northern Venezuela to southern Brazil except for the wet valley of the Amazon. Its length is up to 7 feet. The venom has a largely neurotoxic action, in this respect being different from that of the northern rattlesnakes. It is more aggressive than most reptiles, since it deliberately glides forward toward the intruder. It carries its neck in an S-shaped lateral loop, in readiness to strike. It does not always use its rattle to give warning. While it sometimes coils, with its rattle buzzing steadily, more often it gives no more warning that a few quick side flings of the rattle, producing single harsh clicks. This is a sound well worthy of recognition in the higher ground of the Tropics, as it may be immediately followed by the serpent's stroke with no further warning. This serpent has many common names, the most frequently used being cascabel, although in different parts of Brazil it is called boicininga, maracaboia, and boiquira. It is not found south of southern Brazil and the Chaco region of the Argentine.

\section{The cantil}

The cantil (Agkistrodon bilineatus) takes the place of our water mocassin from central Mexico to Central America. It is dull reddish brown, with wide, dark blotches on the sides outlined by yellowish spots at their borders. The head is dark, with a vivid yellow stripe along the snout and another on the upper lip. It is semiaquatic in habit, and attains about the same size as the related copperhead-less than 4 feet. Its bite is highly toxic: fortunately it does not seem to be abundant. 
The bushmaster

The most feared of tropical American snakes is the bushmaster (Lachesis mutus, pl. 4, fig. 2), the giant among the pit vipers, which attains a length of about 11 feet, although such large individuals are very rare. It is also exceptional among the pit vipers because it lays eggs, all the others bearing the young alive. It is aggressive in character, and while the vibrating of its tail on the ground when the snake is uneasy makes a loud, buzzing sound somewhat like that produced by the warning rattle of the rattlesnake, the bushmaster holds its ground and usually comes nearer to the intruder. Its teeth inject a large quantity of venom, and by their length ( $1 \frac{3}{8}$ inches in a snake 11 feet 4 inches long) they can penetrate very deeply, through coverings that would render the striking of an ordinary-sized snake practically harmless. The body is pale reddish brown with a series of dark blotches, wide on the back and narrow on the sides - a pattern that blends in very well with the surrounding vegetation. Its skin is very rough. It is long and slender, hence well able to travel through underbrush, and its lance-shaped head gives it an extremely sinister appearance. It is found from Nicaragua through southern Central America and South America, also in Trinidad. It is called sirocucu and mapepire in some places where it occurs. It lives in damp forests in holes made by other animals.

\section{The fer-de-lance or barba amarilla}

The fer-de-lance (Botbrops atrox, pl. 5, fig. 1) is another tropical snake which it is well to avoid, as the effects of the poison are said to be

dramatically sinister and rapid, the action being largely haemolytic, destroying the red blood cells, breaking down the walls of the carrying vessels, and producing great extravasation. .... The tissue about the wound is practically dissolved by rapid necrosis. These effects are, however, effectively neutralized by serum produced by the several research laboratories in the tropics. ${ }^{7}$

Its length may be over 8 feet, but average-sized ones are only 3 or 4 feet long. The ground color is variable, from gray to brown or reddish, with a row of dark, light-edged triangles down each side, the tips of the triangles reaching the center of the back. Its body is relatively slender, setting off the lance-shaped head. Since it is not uncommon for a female fer-de-lance to produce 60 to 70 young ones in a litter, the abundance of this species is readily understood. The range extends from southern Mexico through Central America and northern South America, including the islands of Martinique and St. Lucia in the West Indies. Some of its

${ }^{7}$ Ditmars, R. L., Snakes of the world, p. 134, 1934. 
other native names are jararaca, terciopelo (=velvet snake, Costa Rica), and tomigoff (Panama). It is especially dangerous to laborers on sugar plantations, as it is attracted there in numbers by the rats which make their homes in such places.

\section{The palm vipers}

These small snakes (genus Botbrops) are arboreal in habit, being found in the low trees or bushes (pl. 5, fig. 2), sometimes coiled up where the base of a palm stem joins the trunk. Men pushing their way through thick underbrush should be careful to avoid being bitten in the face by these vipers. Their prehensile tail helps them to cross from tree to tree when the branches touch. The green palm viper $(B$. bicolor) is leaf green above and below, and hence is nearly invisible among green foliage. Other species have green, brown, and yellow in the coloring, suited to concealment among branches and leaves. A few of the species have "eyelashes"hornlike projections of the scales above the eye, of no known use to the snake. They are found in Mexico and Central and South America. Because of their often greenish or yellowish coloration and their habit of living in banana trees, these snakes, especially Schlegel's palm viper ( $B$. schlegelii), are extremely dangerous to laborers on banana plantations. Although these snakes are only 2 feet in length, their proportionately large head and long fangs enable them to do more harm than their size would indicate, and fatalities have resulted from their bites.

The jumping viper

Most poisonous snakes in striking keep the tail and posterior part of the body on the ground for leverage, but the jumping viper (Botbrops nummifer) is able to slide and strike in a way that carries its body 2 feet forward. From a slight elevation it is able to jump for a yard. Since its length is somewhat less than a yard, it has several times the striking range of the more stationary fighters among the pit vipers. Its body is stout, its head proportionately large, and its skin so rough that one is reminded of that of the bushmaster. The fangs are short, and the venom is of lower toxicity than in other species of Botbrops, so that this snake is not so greatly to be feared as are most of its relatives. It ranges through most of Central America into Mexico. Its native names are timba and mano de piedra, the latter from its supposed resemblance to the native implement used for grinding corn. 


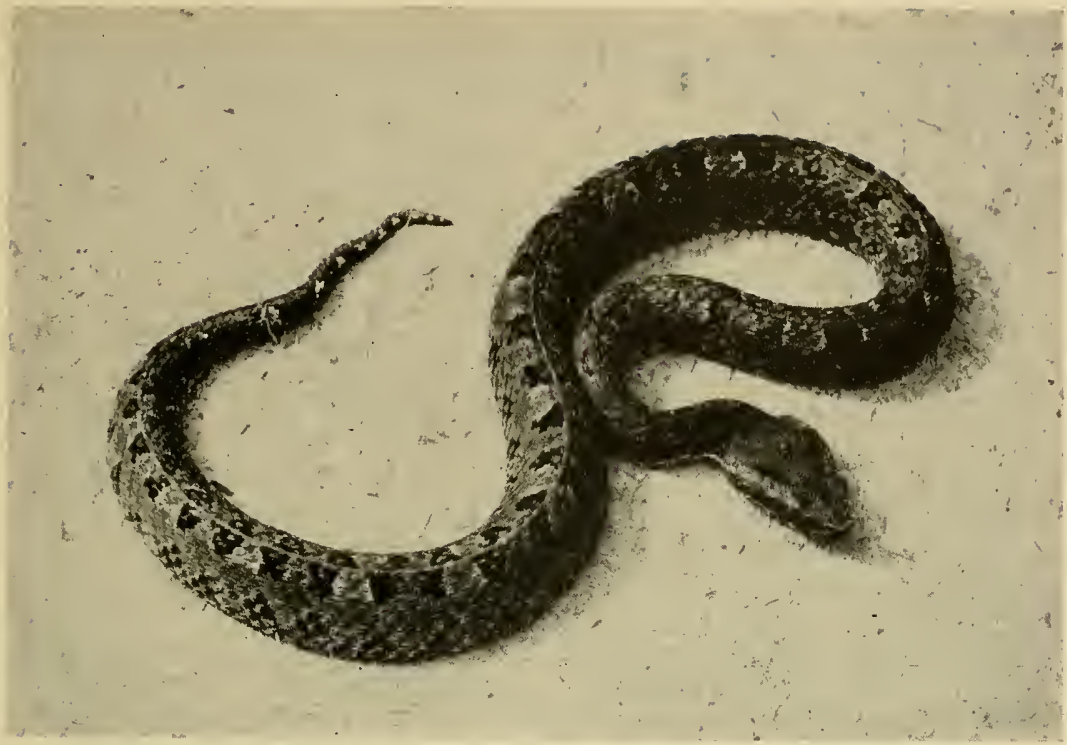

Courtesy Nature Magazine

1. Hognosed viper (Botbrops nasuta), also called nose-horned viper. Color: brown with alternating small black spots along the back separated by a pale line. Length: 2 feet. Range: eastern Central America to Colombia and Ecuador.

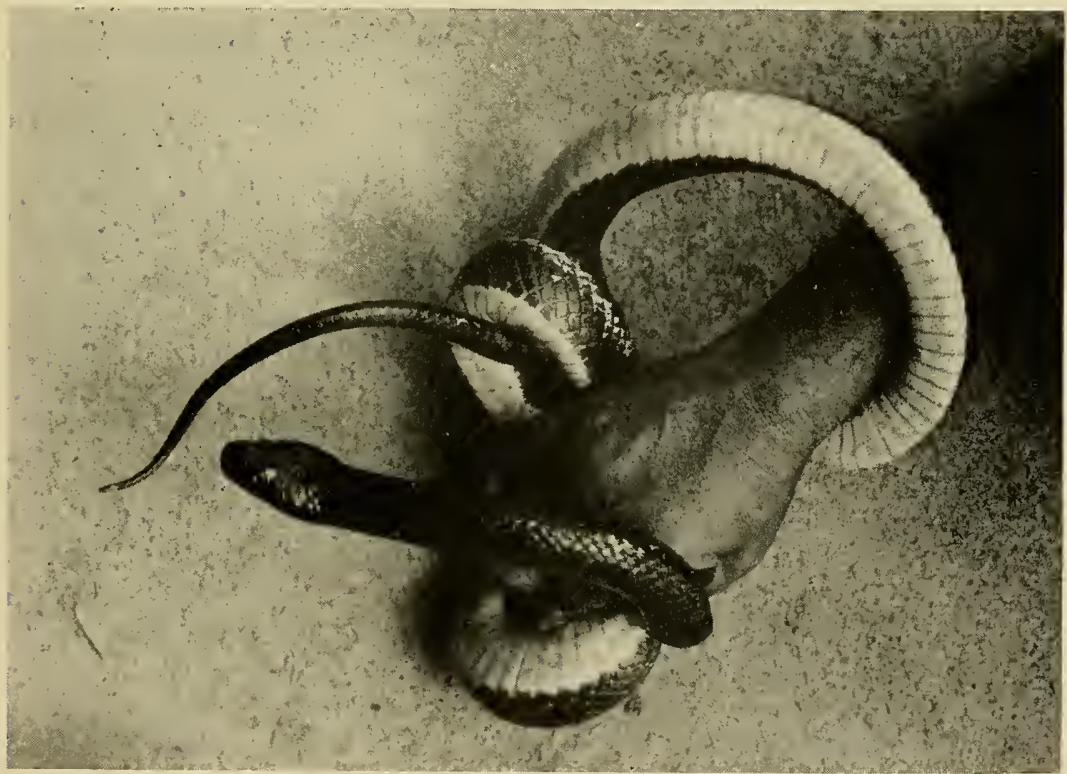

Courtesy Nature Magazine

2. Mussurana (Pseudoboa cloelia), a beneficial snake because of its habit of eating other snakes, especially the fer-de-lance. Color: blue black above, white below (Central American specimens). Length: 8 feet. Range: Guatemala through Brazil. Back-fanged, but the bite not fatal to man. 


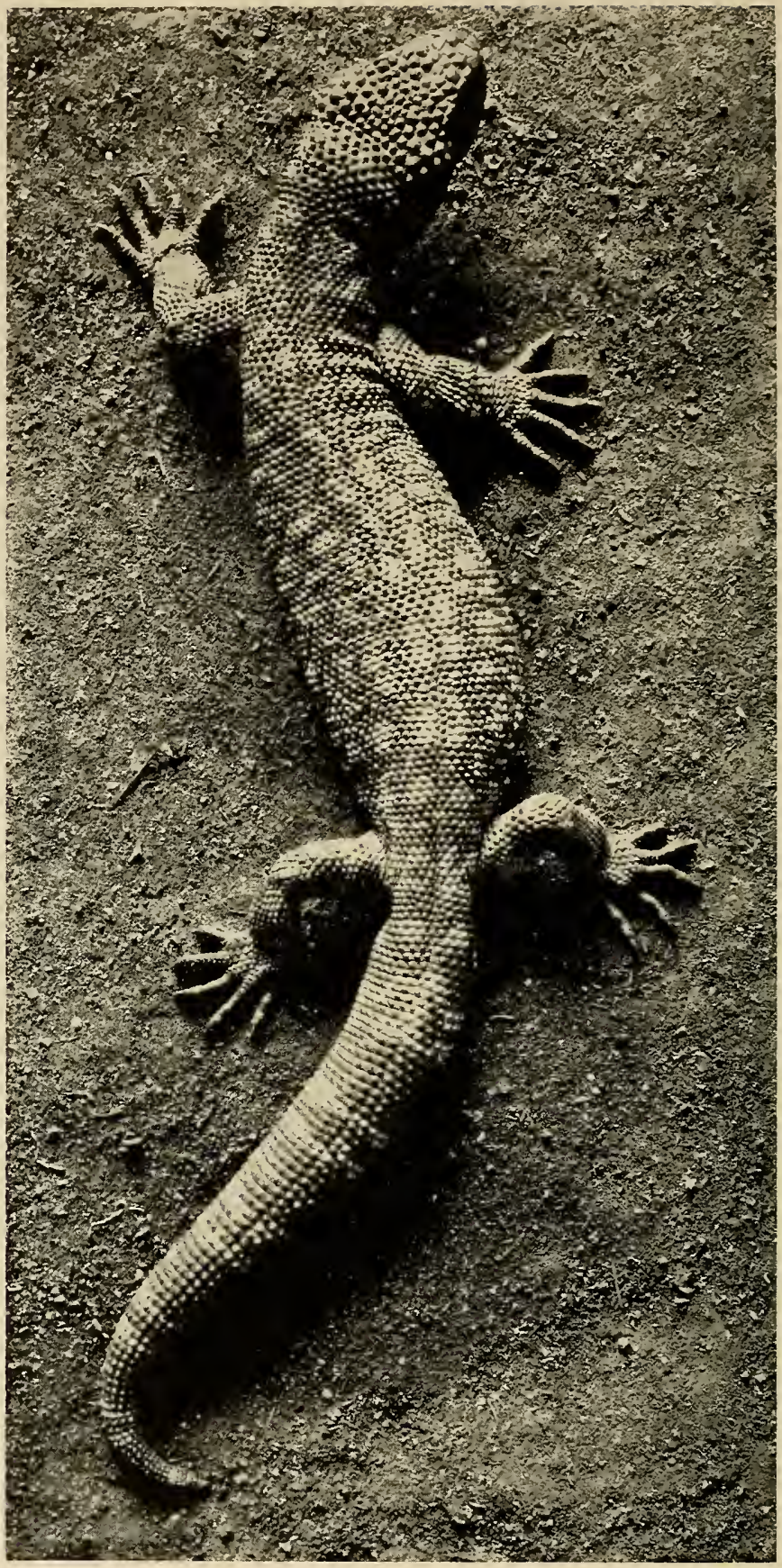

Mexican beaded lizard (Heloderma horridum). Color; yellow with dull brown or black irregular markings. Length: $2 \frac{1}{2}$ feet. Range: Central Mexico to northern Central America. Not aggressive unless disturbed. 


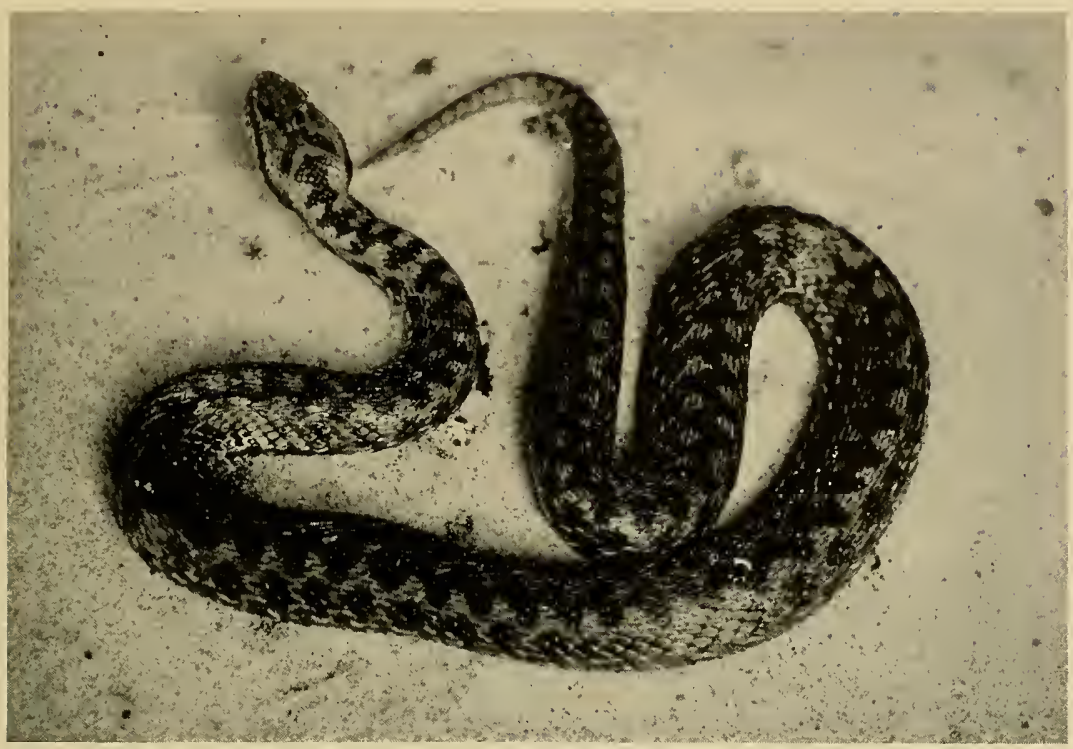

Courtesy New York Zoological Society

1. Common viper (Vipera berus), also called adder or kreuzotter (in Germany). Color: gray, olive, brown, or reddish, uniform or with small dark lateral spots; a dark zigzag pattern along the back. Length: over 2 feet. Range: Great Britain; northern Europe, and Asia to the Amur River and Sakhalin Island; southward in Europe to the Pyrenees, the Apennines, and the Balkans. Dangerously poisonous, savage, and quick.

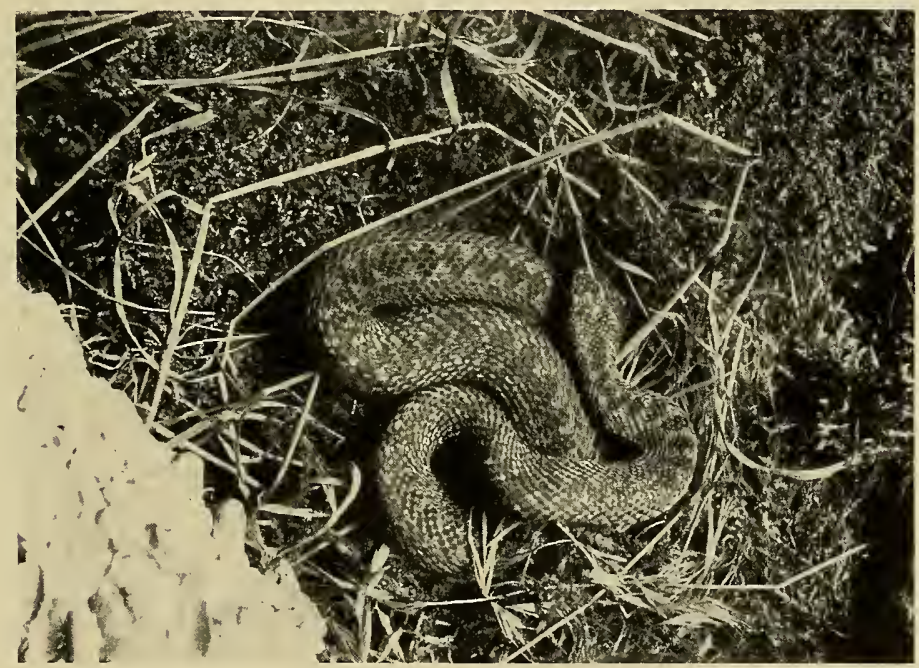

Courtesy Bulletin of the Antivenin Institute

2. Orsini's viper (Vipera ursinii), also called marasso alpino in Italy. Color: yellowish or pale brown with a series of dark brown spots which may run together in a wavy or zigzag band; sides dark gray or brown. Length: 2 feet. Range: southern France, northern Italy, Hungary, and parts of Jugoslavia. Slightly poisonous; not aggressive. 


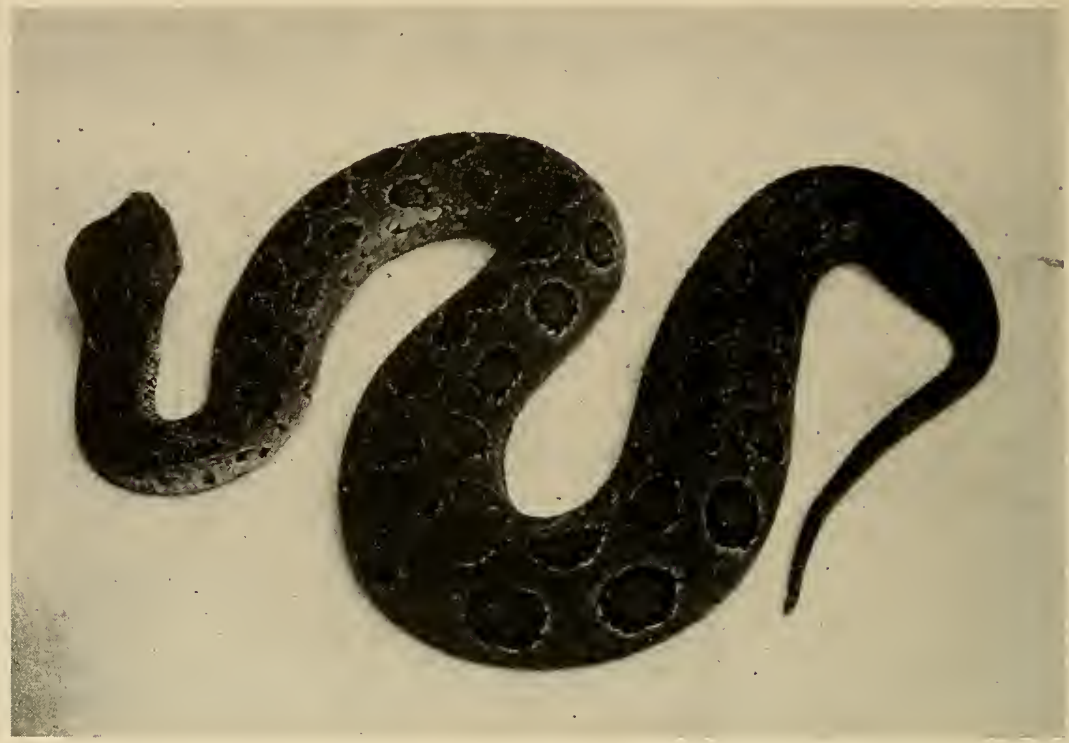

Courtesy New York Zoological Society

1. Daboia (Vipera russellii), also called Russell's viper or tic-polonga. Color: pale brown, with 3 rows of large black rings bordered with white or yellow, having red or brown centers. Length: 5 feet. Range: India, Ceylon, China, the Malay Peninsula, and some of the East Indian islands. Extremely poisonous; not aggressive unless disturbed.

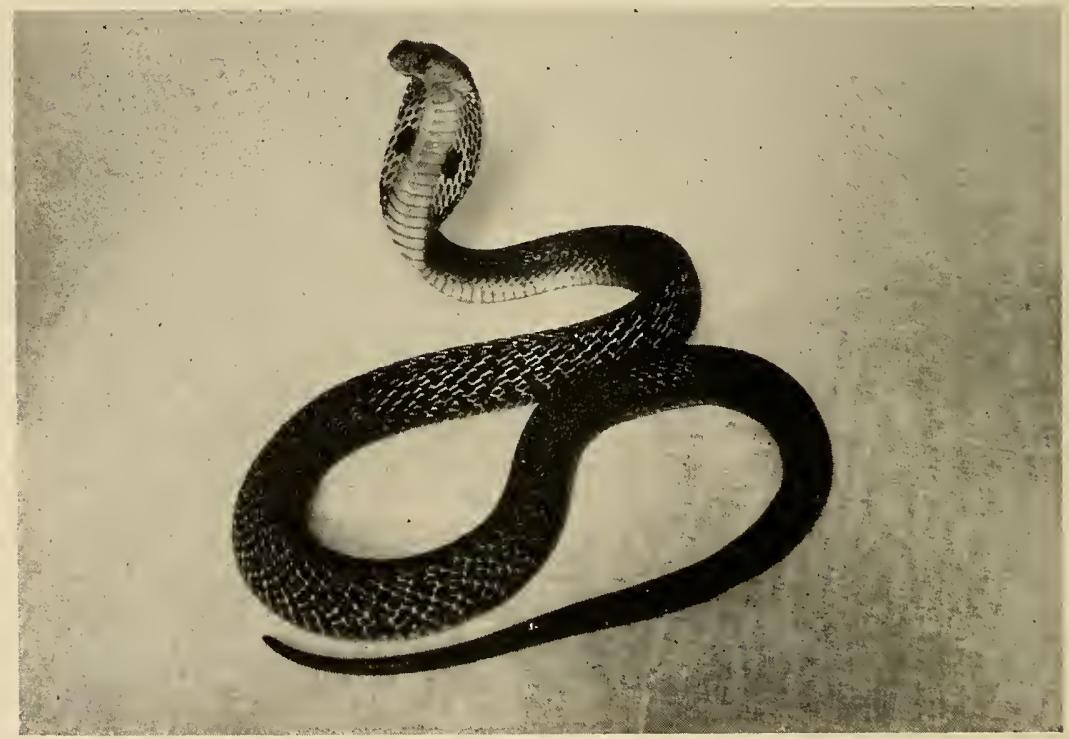

Courtesy New York Zoological Society

2. Indian cobra (Naja naja), also called spectacled or Asiatic cobra. Color: yellowish to dark brown, with a black and white, usually spectacle-shaped mark on the back of the hood when spread. Length: 6 feet. Range: eastern shores of Caspian Sea through Asia into China and Formosa, the Malay Archipelago, and the Philippines. Exceedingly poisonous; aggressive when disturbed. 


\section{The hognosed vipers}

These three small terrestrial vipers (Botbrops nasuta, B. lansbergii, $B$. ophryomegas) may be recognized by their upturned snouts (pl. 6, fig. 1) . They live in Central America and southern Mexico, with two species extending into northern South America. Their native names are chatilla or tamagá. Some of these savage little vipers strike with such force that they slide a few inches on smooth level ground and sometimes jump forward several inches, although this habit is not so characteristic of them as it is of the true jumping viper (Bothrops nummifer) mentioned above. They grow to about 2 feet in length.

\section{Other pit vipers}

Maximilian's viper (Bothrops neuwiedii) of Brazil is of the fer-de-lance type and might be mistaken for that species. But it is usually smaller, and details of the triangular brown markings are different. Its native names are jararaca and urutu. It ranges also into Argentina and northern Paraguay. The name jararaca is also applied to other closely related kinds of poisonous snakes.

One of the most poisonous of all the pit vipers is the island viper (B. insularis), which is confined to a small rocky island barely threequarters of a mile in extent lying 40 miles southwest of the Bay of Santos. Since there is little else on the rock for snakes to eat except the small birds that nest there, this snake's highly toxic bite evidently insures the death of the bird before it has been able to flutter far enough to fall into the sea and so be lost.

While most people do not associate beauty with a poisonous serpent, b. alternatus, commonly called urutu, has one of the handsomest patterns of all the pit vipers--a series of dark brown crescentic marks on each side, on a pale cream ground color. It grows 5 feet in length, with a thick, heavy body. It occurs in southern Brazil, Paraguay, Uruguay, and the Argentine.

The value of using scientific rather than common names for species is well illustrated by my attempt to give the Indian names for some of the foregoing snakes. The word jararaca is used for several different kinds of pit vipers. The same is true of urutu. Likewise it will be seen that the name copperhead is used for an Australian snake of a different family from that of the copperhead found in the United States. Scientific names need be no stumbling block after their necessity has been fully proved. 


\section{The Semipoisonous Tree Snakes}

Some of the opisthoglyph (=back-fanged) snakes (Oxybelis, Pseudoboa) have also taken to an arboreal existence. These are less dangerous to man because of the small amount of poison, its relative mildness, and the fact that the teeth placed in the rear of the mouth do not always make good contact with a victim's flesh. Most of these snakes are slender and whiplike in body, with elongate heads and large eyes. Some are green, others grayish or brown in color. The green whip snake, Oxybelis fulgidus, is light green with a lemon-yellow stripe on the sides. When frightened, it stiffens its neck and slowly waves its head from side to side to imitate a stem blown by a breeze. Its food consists of lizards, which are very susceptible to its poison.

The mussurana (Pseudoboa cloelia, pl. 6, fig. 2) is a large, heavy-bodied serpent which uses its constricting powers as well as its poison to subdue its prey. Its chief food consists of other snakes, among them being the deadly fer-de-lance - not deadly at all to the mussurana, which is unaffected by the poison or the injuries of the fangs. Unfortunately, the mussurana is rather rare throughout its rather wide range-Guatemala through Brazil. Most of the natives know of its snake-eating habits, and so it is seldom killed. Brazilian specimens are blue black all over, while Central American ones are white beneath. Young ones are said to be coral red.

\section{The Yellow-Bellied Sea SNake}

Only one species of sea snake (Pelamydrus platurus, fig. 2) has crossed the Pacific Ocean from its native home off the coast of Asia. This snake is more compressed in form, with very small scales and no enlarged plates across the ventral region. Its back and upper sides are rich brown to black, sharply set off from the bright yellow ventral coloration. Its tail is compressed and rounded at the tip like a paddle and acts as a rudder. While this species seldom exceeds 3 feet in length, some of the other species (to be discussed in the section on Asia) are more than twice as long. Fatalities from its bite have been reported, but as a rule sea snakes are disinclined to bite, although some are equipped with very deadly poison, and are said never to attack bathers. Their food consists of fish and other small marine organisms. They are now established along the west coast of Central America, especially in the Gulf of Panama.

\section{The Mexican Beaded Lizard}

The Mexican beaded lizard (Heloderma horridum, pl. 7) is the only other known species of poisonous lizard in the world, besides its relative, 
the Gila monster. It occurs from the central part of Mexico to the northern part of Central America. Its habits are very similar to those of its northern relative, but it is a little larger, being known to reach 30 inches in length, and its tail is proportionately longer. Its head is usually black, and its beadlike scales are colored with irregular patches of black and yellow. The very young lizard has vivid yellow stripes, with bands of yellow on the tail. With age this regular pattern disappears, and some specimens turn nearly black or dark brown. The bite brings the same poisoning symptoms as that of the Gila monster.

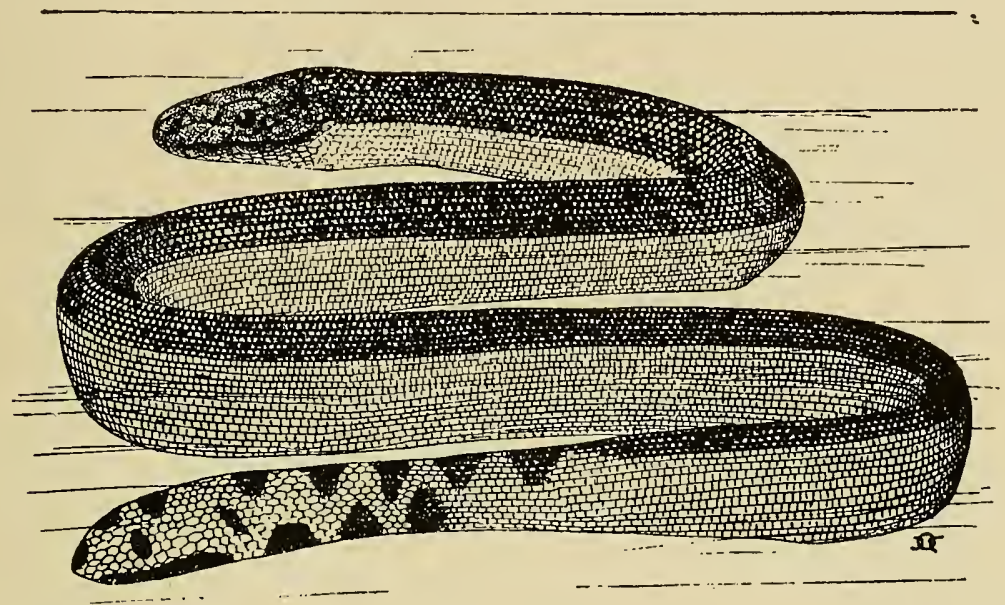

FIG. 2.-The yellow-bellied sea snake (Pelamydrus platurus), entirely aquatic, and having a compressed, rudderlike tail.

\section{POISONOUS REPTILES OF THE OLD WORLD}

The family Viperidae (=true vipers) is as characteristic of the Old World fauna as are the rattlesnakes of the New World. Some representatives of the Crotalidae, the family to which the rattlesnake belongs, are found in southeastern Asia and the East Indies, however. These are pit vipers, and differ from the true vipers which are likewise found in those regions by the possession of a complex pit on the side of the head between eye and nostril. Both these families differ from the following ones in having a head distinctly set off from the body by the swelling at the base of the jaws due to the presence of poison glands.

The family Elapidae, represented in the New World by the coral snakes, contains some of the most widespread and dangerous of Old World snakes-the cobras. Australia, with about 80 kinds, is the headquarters of the family, while Africa and southern Asia boast of numerous species 
also. The Elapidae have the head and body nearly continuous in outline, with no distinctly marked "neck" in most cases, in this respect resembling the harmiess colubrine snakes.

The Hydridae (=sea snakes) are found near the coasts of southern Asia and northern Australia. Most of them hug the shore and dislike to swim far away from land. One kind has successfully crossed the Pacific and established itself on the west coast of Central America, as stated above, and this same species has likewise crossed the Indian Ocean to the eastern shores of Africa.

Some rear-fanged snakes of the family Colubridae occur in Asia, but as their bites are not deadly to human beings, they will not be discussed here.

While no poisonous lizards are positively known from the Old World, an exceedingly rare lizard from Borneo possibly related to the Gila monster has been assumed to be poisonous. As yet no proof of this has been put forward.

\section{EUROPE AND NORTHERN ASIA}

The true vipers (genus Vipera) are the only poisonous snakes to be found in Europe and northern Asia. Some of their characteristics are a vertical pupil, relatively small size, and a zigzag dark stripe down the middle of the back more or less pronounced in European species. These vipers fall naturally in groups of closely allied species which have much in common.

The common viper and its allies

This snake (Vipera berus, pl. 8, fig. 1), called northern viper or adder in part of its range, is the only poisonous species inhabiting the British Isles, where it is found in Scotland, Wales, and England, but not in Ireland. It likewise ranges over northern Europe at least to the 67th degree in Scandinavia and across northern Asia to the Amur River and Sakhalin Island. Southward it extends to the Pyrenees, Apennines, and the Balkans. Two distinct forms occur in different parts of Jugoslavia, while another lives in northwestern Spain and Portugal. It prefers a cool climate, but in the north selects hills well exposed to the sun on which to bask, although it is partially nocturnal also. It eats any small living creatures of suitable size-mice, birds, lizards, frogs, salamanders, and slugs, while the very young ones feed on insects and worms. The young are born alive in August or September, and number from 5 to 20 in a litter. Many fatalities from the bite have been recorded, especially in France and Ger- 
many. Exceptional specimens are nearly 3 feet long, although 2 feet is the more usual length.

\section{Orsini's and Renard's vipers}

Orsini's viper ( $V$. ursinii, pl. 8, fig. 2), rather similar to the common viper in appearance, is found in southern France, northern Italy, Hungary, and parts of Jugoslavia. It is not found with the common viper in any part of its habitat. It grows to a maximum size of 2 feet. Its disposition is much less aggressive than that of the common viper, and in some places it is said not to make use of its poison apparatus since it feeds entirely on grasshoppers. Renard's viper ( $V$. renardi) is closely related, except that its snout is much more pointed. Its length does not exceed 2 feet. It is found in the Crimea and parts of eastern Russia, extending far into Central Asia. Its food consists of small mammals and lizards.

The asp, Lataste's and the long-nosed vipers

These three European vipers can be recognized by their "turned-up noses," that is, the tip of the snout is distinctly above the level of the top of the head. The asp viper ( $V$. aspis) is found in southern France, the Pyrenees and Apennines, and Jugoslavia. It likes hot, dry localities, and lives in a hole in a rock or in the earth. It is both nocturnal and diurnal, with food habits similar to those of the common asp. Its disposition is savage, and many accidents, some of them fatal, are caused yearly in southern France where it is very abundant. A subspecies occurs in Sicily and Calabria (southern Italy). Lataste's viper ( $V$. latasti) prefers stony, arid, and forested regions in Spain and Portugal, also in Morocco and Algeria. ${ }^{71}$ It is not known to exceed a length of 2 feet. It climbs low trees in search of young birds. Its bite is supposed to be less dangerous than that of the asp viper and rarely causes the death of human beings or domestic animals. Its nose is likewise somewhat "turned up." In the sand viper or long-nosed viper ( $V$. ammodytes) the snout appendage is particularly evident, giving it one of its common names. It occasionally grows to a length of 3 feet. It has numerous geographical varieties. The typical form is found in Austria and the Balkan States. It likes dry, stony hills with low bushes, which it frequently climbs. Its poison is stated to be more active than that of other European vipers, so that fatal accidents to man are frequent. It is extremely abundant in some parts of Austria and is said to be the commonest of all snakes in Bosnia and Herzegovina. A closely related form (Vipera ammodytes meridionalis) takes its place in Greece and European Turkey. 
The blunt-nosed viper and its allies

The blunt-nosed viper ( $V$. lebetina lebetina), also called kufi, is found on the island of Cyprus and in Europe on Melos (one of the Cyclades Islands), and has an extensive range in Asia and Africa. Some poorly defined varieties occur, among them a form called xantbina from Asia Minor and others named mauritanica and deserti from Morocco, Algeria, and Libya. Large examples are $4 \frac{1}{2}$ or 5 feet long. They live in rocky regions and are nocturnal in habit.

\section{INDIA AND MALAYA}

This region is very well provided with poisonous snakes. Representatives of the Viperidae (true vipers), Crotalidae (pit vipers), Elapidae (cobras and kraits), Hydridae (sea snakes) and Colubridae (colubrine snakes) are found here, comprising examples of all existing families containing dangerous poisonous snakes. The most spectacular are the cobras, although the daboia (or Russell's viper) is one of the commonest and deadliest snakes of India.

\section{The Vipers}

Although the total number of species known from Asia is not large, this family (Viperidae) represents some of the most dangerous of all poisonous snakes. The fact that most vipers produce living young, and hence are not subject to the many checks to increase that the egg-laying snakes have to undergo, has caused certain regions in India and Africa to be populated very heavily by vipers.

The daboia, the tic-polonga or Russell's viper

This beautiful serpent ( $V$. russellii, pl. 9, fig. 1), more than 5 feet in length at its maximum, is pale brown with three longitudinal series of yellow-bordered black rings enclosing spots of chocolate brown. A very loud warning hiss is given when the snake is disturbed. It will not strike until considerably irritated, when it hurls itself to the attack. The venom is secreted in large quantities, a 3 -foot snake having been estimated to inject about twice the lethal dose for man at one bite. The snake is found nearly everywhere except in dense jungle, preferring open, sunny regions. It is nocturnal in habit and feeds by choice upon rats and other small mammals. It is found in India, Ceylon, Burma, Siam, the Malay Peninsula, and southern Yunnan in China. The period of gestation is more than 6 months, the litter of about 30 young being born usually in June and July, when they are less than a foot long. 
The carpet or saw-scaled viper

This little snake (Echis carinatus) burrows in the sand to hide, hence preferring sandy places throughout its range through Syria and Persia into India. Its common name, "saw-scaled," is given by reason of the fine, sawlike "teeth" down the center of the lateral scales. It reaches a length of 2 feet, but in spite of its small size it is very fierce and aggressive.

A related species, E. coloratus, is known from Arabia and Palestine.

Another small viper of a different genus (Azemiops feae) grows to a length of 2 feet. It is extremely rare, only about four specimens ever having been collected in Upper Burma and in southern China (Szechwan and Kiangsi). It resembles a harmless colubrine snake in appearance, being blackish above with 15 narrow transverse white bands. Nothing is known about its venom.

\section{The PIT Vipers}

Asiatic members of this family (Crotalidae) used to be considered as part of the family Viperidae. A more correct estimate of their distinctness is obtained by putting them into the family of which the New World rattlesnake is the representative. The Old World crotalids, however, do not have any rattle. They belong to the same genus as do the copperhead and moccasin described under North American poisonous snakes.

\section{The mamushi and its relatives}

This snake (Agkistrodon blomboffri) is restricted to the Japanese islands, although close allies are found on the Asiatic mainland. Average specimens are about 20 inches long. The pattern consists of a series of dark brown rhomboid blotches on each side near the center of the back, separated by a pale grayish band which lightens nearly to white next to the dark blotches. Some specimens are much darker.

One of the most poisonous species in the genus is A. rbodostoma, found in Malaya. Its pattern is very striking - angular, dark brown, black-edged markings on a reddish-brown background. The snout is pointed, and as the posterior part of the head is widened, the serpent has a very sinister "lance head."

Some of the other species are very abundant. Agkistrodon balys and its relatives are the commonest poisonous snakes in China and the Himalayan region west almost to southeastern Europe. 
Bamboo snakes and their allies

Some of the Asiatic members of the genus Trimeresurus closely correspond to the palm vipers of tropical America. They are the arboreal species with prehensile tails and green coloration, such as Trimeresurus gramineus, the bamboo viper, and its relatives. Some species of Trimeresurus are terrestrial, and these are also like Bothrops of the American Tropics. The head is always broad and distinct from the neck, while the body is not very stout in this genus. The arboreal species are particularly slender. The fangs are proportionately very long, and the bites are dangerous, although the venom is not quite so toxic as that of some of the true vipers. The habu (Trimeresurus flavoviridis) grows to a length of 5 feet in the Riu Kiu Islands, and its bite is considered to be very serious.

\section{COBRAS AND KRAITS}

These snakes (family Elapidae) are slender in build, with the head scarcely enlarged. Some species of cobras have more or less inflatable "hoods" behind the head, produced by moving the ribs forward inside the loose skin.

\section{Indian or spectacled cobra}

This snake (Naja naja, pl. 9, fig. 2) is probably the best known of any of the poisonous snakes of Asia and is vastly more deadly and more feared than the others. It grows to be about 6 feet long, and is yellowish or dark brown in color, with a more or less spectacle-shaped black and white marking on the raised hood. Occasionally the hood has no pattern, sometimes there is a single spot. The cobra is nervous and excitable, spreading the hood and arching the neck when disturbed. It strikes with a forward sweep of its raised body, accompanied by a sharp hiss. This striking is not nearly so quick as the darting of a viper's head, which strikes laterally from the bent neck. The cobra becomes irritable, sometimes gliding forward to attack its enemy, but there is no deliberate rush, and the snake can be held off with a light stick. When it bites, it retains its hold just as the coral snake does, since the fangs are relatively short, and a larger amount of poison can enter the wound with the longer contact. The cobra feeds on rats, mice, and frogs by choice, and often takes up its residence in the dark corners of a native hut in order to prey upon the rodents attracted to human habitations. This snake is accountable for more deaths from snake bite than any other species. It is impossible to state accurately just how many people in India die each year from its 


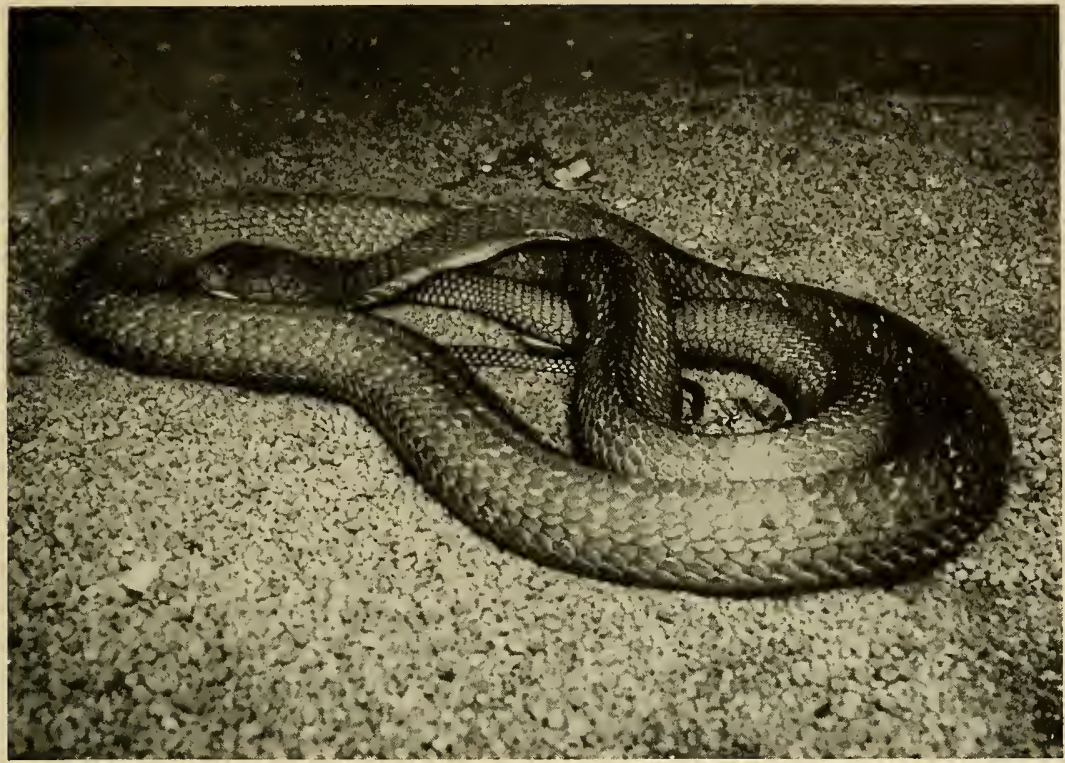

Courtesy New York Zoological Society

1. King cobra (Naja bannab), also called hamadryad. Color: olive or yellowish brown, often with black cross bands. Length: over 18 feet. Range: eastern India, China, the Malay Archipelago, and the Philippines. Extremely dangerous; very aggressive.

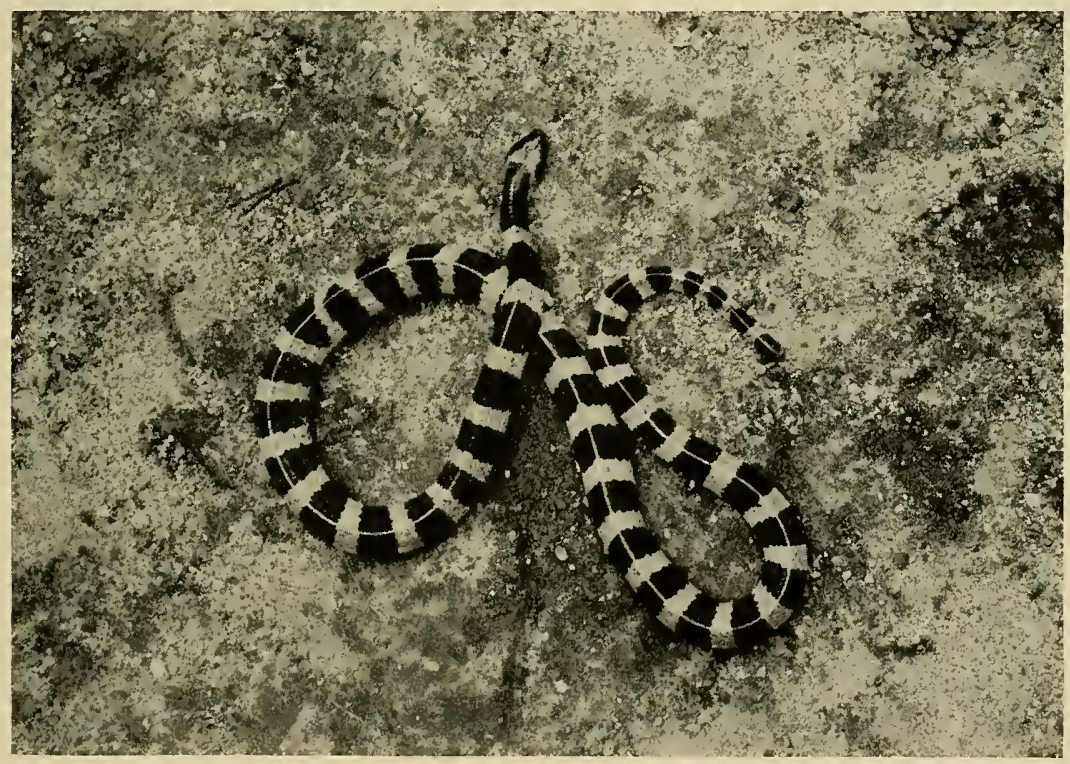

Courtesy New York Zoological Society

2. Banded krait (Bungarus fasciatus), also called ular welang in Malay. Color: yellow above, with broad black rings. Length: nearly 5 feet. Range: southern India and China, the Malay Peninsula, Sumatra, and Borneo. Extremely poisonous; not aggressive unless disturbed. 


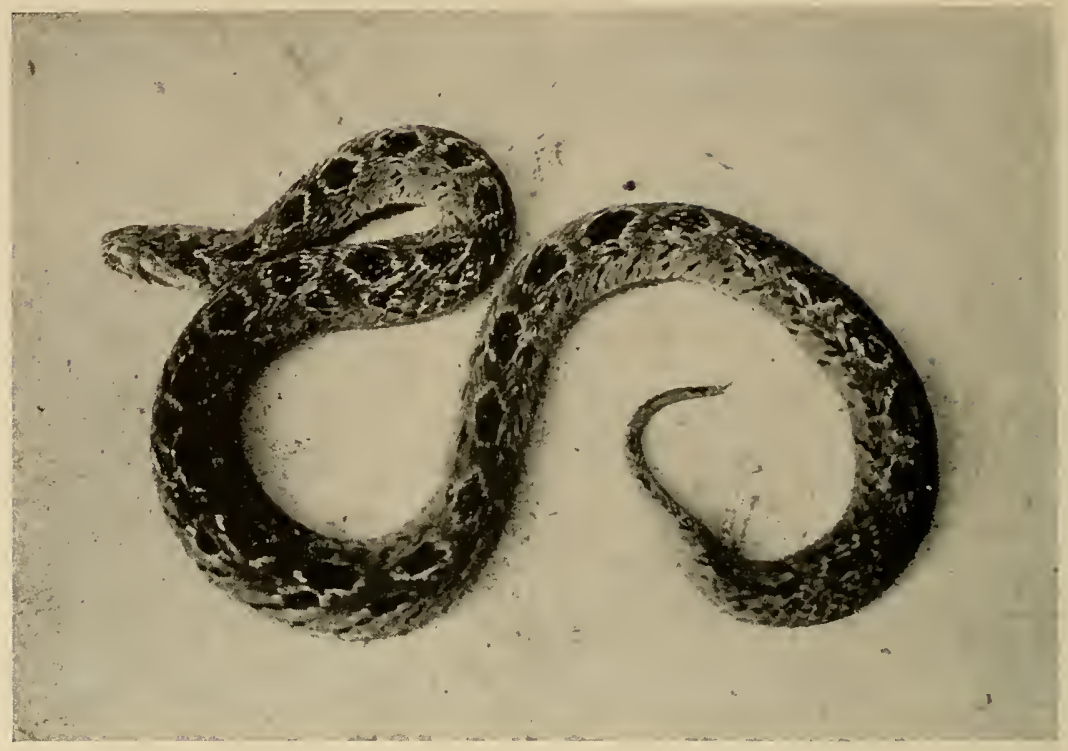

Courtesy New York Zoological Society

1. Night adder (Causus r hombeatus), also called Cape viper. Color: gray, with a chain of dark, light-edged spots along the back. Length: 3 feet. Range: the greater part of South Africa to the Nile. Extremely poisonous, aggressive when disturbed.

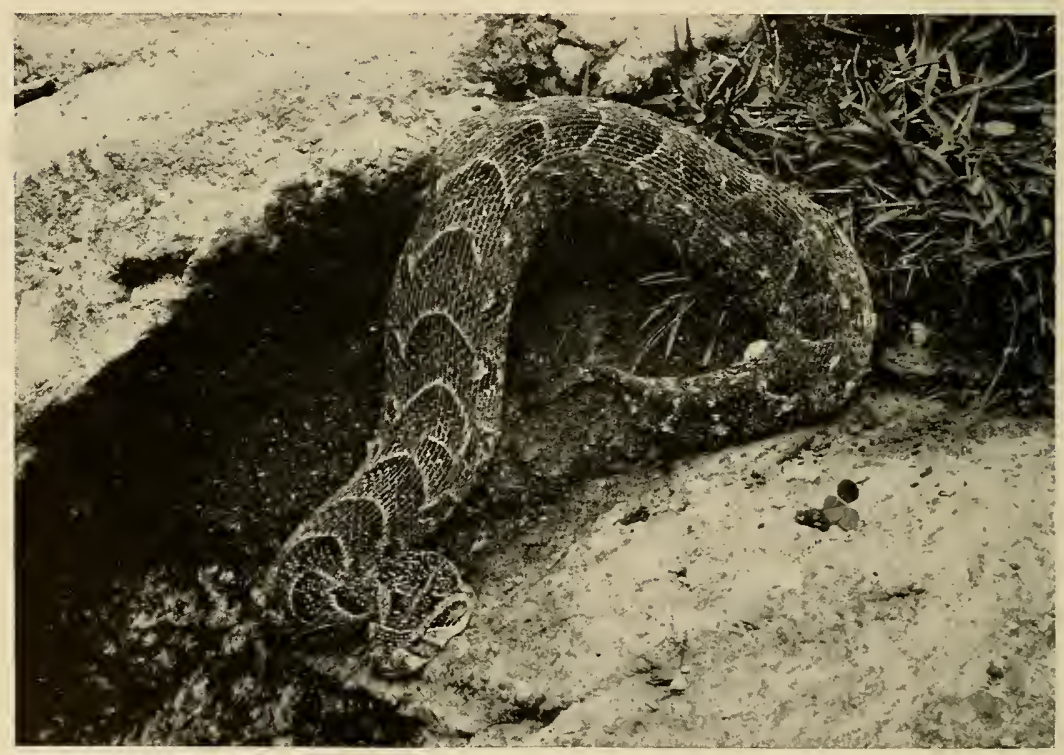

Courtesy New York Zoological Society

2. Puff adder (Bitis arietans). Color: a series of black chevrons separated by yellow crescents down the back. Length: 5 feet. Range: southern Morocco and the southern Sahara to the Cape of Good Hope, also Arabia. Extremely poisonous; hisses loudly when disturbed. 


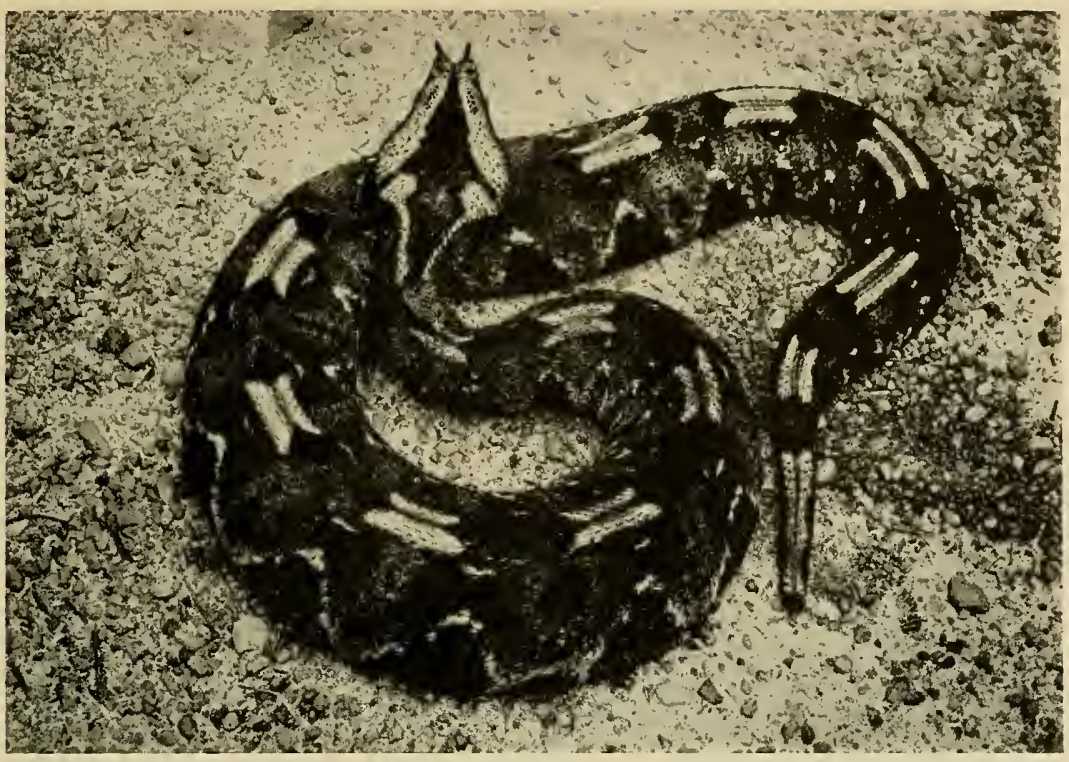

Courtesy New York Zoological Society

1. Rhinoceros viper (Bitis nasicornis), also called river jack. Color: a row of large blue oblong marks down the back, with a yellow line in the center and black borders; a series of dark crimson triangles bordered with blue on the sides; top of head blue with a black arrow-shaped mark pointing forward. Length: 4 feet. Range: tropical West Africa. Extremely poisonous, but not aggressive.

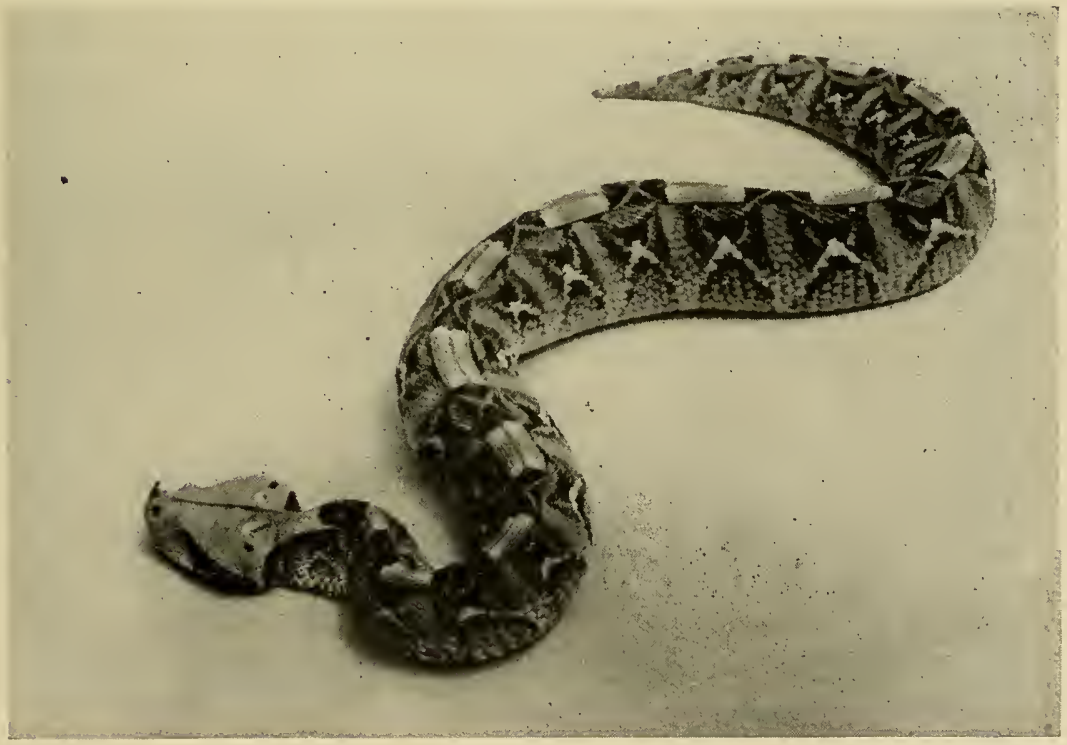

Courtesy New York Zoological Society

2. Gaboon viper (Bitis gabonica). Color: a series of oblong buff marks enclosed in brown ovals along the back, with a chain of purplish marks outside of these; sides with triangular purplish blotches; eyes silvery. Length: nearly 6 feet. Range: forests of West Africa, also Uganda, Tanganyika, Northern Rhodesia, Angola, and the island of Zanzibar. Extremely poisonous. 


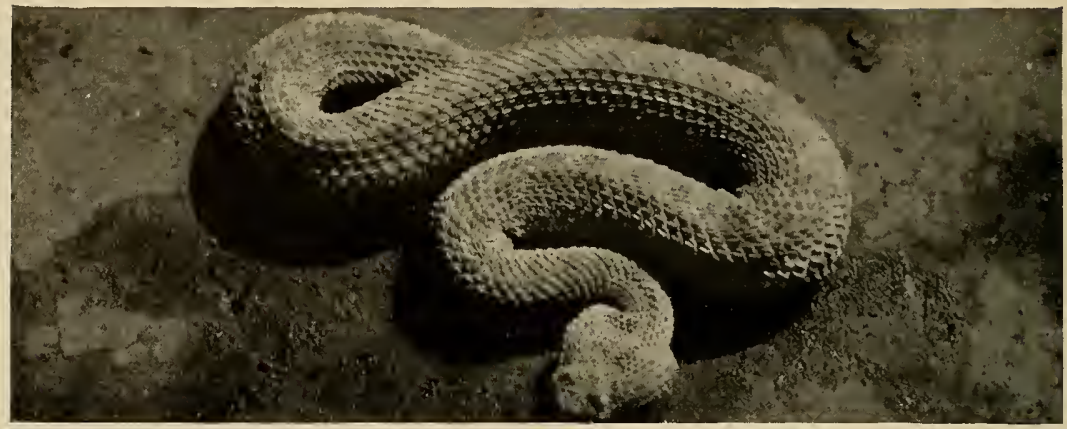

Courtesy New York Zoological Society

1. Common sand viper (Aspis vipera). Color: pale yellowish or pinkish to match the desert sand, with faint darker blotches. Length: about 2 feet. Range: northern Africa from Algeria to Egypt.

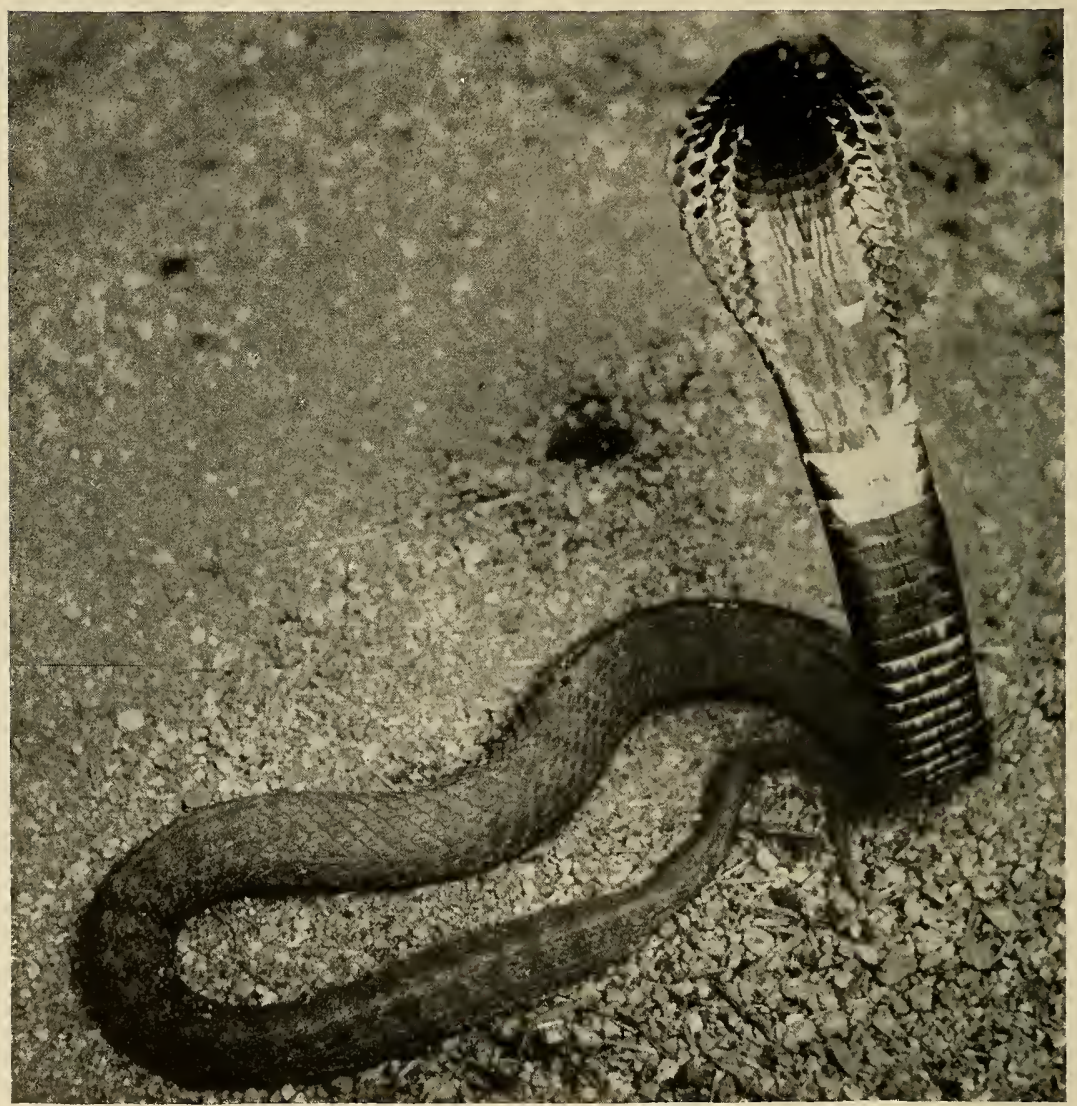

Courtesy New York Zoological Society

2. Ringhals (Haemachates haemachatus), also called keel-scaled spitting snake. Color: brown or dull black above, sometimes with cross bars of brown; underside blackish, except for a pale band or two on the neck. Length: about 4 feet. Range: Cape of Good Hope and Namaqualand. Dangerously poisonous not only from the bite, but from its habit of spraying poison in the eyes of its victim, and very aggressive. 
bite. Owing to the natives' habit of going bare-legged, especially at night, fatal accidents from cobra bite are unnecessarily numerous. On plantations where the natives are made to take precautions, and where serum is available, fatalities have greatly decreased. The Indian cobra and its very closely allied subspecies occur from the eastern shores of the Caspian Sea through Asia into China and Formosa, the Malay Archipelago, and the Philippines.

\section{The king cobra or hamadryad}

The king cobra (Naja bannah, pl. 10, fig. 1), largest of all poisonous snakes, has been authentically reported as reaching a length of 18 feet 4 inches. While its anterior ribs are elongated, it cannot spread a hood nearly so wide proportionately as that of its smaller relative. It feeds almost exclusively upon other snakes, and probably ranks first as a wholesale destroyer of snakes, taking kraits and smaller cobras along with the harmless species. It occurs in eastern India, China, and the Philippines, as well as the Malay Archipelago. It is diurnal and lives in dense jungles near streams, sometimes climbing trees. It is said to be fearless and may attack human beings when disturbed. It lays from 21 to 33 eggs on a pile of leaves, and these eggs are guarded by the female. In captivity it displays an intelligence very unusual in snakes by learning, after a very few days, not to strike its head against the glass of its cage. The color is olive or yellowish brown, often with black rings on the body.

\section{The kraits}

The common krait (Bungarus candidus) grows to a maximum length of 4 feet. It is lustrous black or brown above, with narrow white bands across the back; below it is pearly white. It is one of the most numerous snakes where it occurs and likes to live near human dwellings, also in fields or low scrubby jungle near water. Its food consists almost entirely of other snakes, occasionally frogs, lizards, and small mammals. It is one of the most inoffensive of snakes, hiding its head beneath the coils of its body and refusing to move when teased. Like the cobra, it lays eggs, 6 to 10 in a clutch, usually in soft earth. Experiments show that its poison is four to five times as virulent as that of the cobra. It has a wide distribution throughout India and the Malay Archipelago to Formosa and southeastern China. Members of this genus can be recognized by their ridged backbone, on which there is a row of widened, enlarged scales. They are nocturnal in habit.

The banded krait (Bungarus fasciatus, pl. 10, fig. 2) prefers jungle dis- 
tricts. It is ringed with yellow and black bands. It is even more sluggish than the common krait and occurs over the same area.

\section{The Sea SNakes}

The sea snakes (family Hydridae) live in the tropical parts of the Pacific and Indian Oceans. They occur along the coast of Asia from the Gulf of Persia to southern Japan, among the islands of Oceania, and to the coast of tropical Ausiralia. All the species but one stay close to the shallow waters near the coast, especially near river mouths. They feed entirely upon fish. Those sea snakes with the smallest heads and slenderest bodies limit their diet to eels. Sometimes on a calm day they are to be seen, often in hundreds, basking upon the surface of the water. Their structure is well adapted to an aquatic existence, since the tail has become compressed and rudderlike, while the ventral plates are much reduced in most of the species, appearing like the rest of the small scales covering the body. The poison of at least one of the species is known to be more deadly than that of the cobra, while some are said to be only slightly poisonous. They are not inclined to bite except when forcibly restrained, and are said never to attack bathers in the water. Fishermen are sometimes bitten when they haul in a sea snake along with their net of fish, and sometimes fatalities result, because these fishermen do not think of seeking trained medical assistance. All sea snakes bear their young alive, 2 to 18 at a time, in tide pools and shallow flats of deserted shores. Few sea snakes exceed 4 feet in length, although examples of two species have been found measuring nearly 9 feet.

\section{AFRICA}

The Dark Continent has nearly as great an array of poisonous serpents as is found in Asia. While the king cobra of southern Asia claims the record of being the world's largest poisonous snake, Africa has the distinction of having produced two kinds of spitting snakes - both cobraswhich blow their venom into the face of the attacker from a distance up to 12 feet. Africa is the home of about 30 kinds of true vipers also, some of them very peculiar.

Since sea snakes do not occur in Atlantic waters, it is only on the east coast of Africa that we find an occasional example of the same far-traveling species that occurs on the western coast of Central America.

No pit vipers occur in Africa. The remaining family containing dangerous poisonous snakes is the Colubridae, of which one section, the rearfanged snakes, is represented in Africa by the boomslang.

No poisonous snakes are found on the island of Madagascar. 


\section{THE V1PERS}

The night adder or Cape viper

As its name indicates, this snake (Causus rbombeatus, pl. 11, fig. 1) emerges at night to hunt for rats, mice, and toads. It is rather inoffensive, and unless hurt or frightened, it does not attempt to bite. It grows to be about 3 feet long. It is yellowish or gray in color, with a chain of dark, light-edged spots along the back, and smaller ones on each side. There is a dark chevron at the back of the head. The snake hides in rubbish heaps, rock piles, or shallow holes when not hunting. It frequently enters farm houses in its search for rodents. It is very common around Nairobi, and extends from the Nile over the greater part of South Africa. The poison is not so highly toxic as in many of the other vipers. A peculiar anatomical feature is the extension of the poison glands into the neck to several inches behind the head. Another interesting peculiarity is that this snake and others of this genus lay eggs, while most of the other vipers are viviparous.

The puff adder

This snake (Bitis arietans, pl. 11, fig. 2) is one of the most widely distributed in Africa, being found all the way from southern Morocco and the southern Sahara to the Cape of Good Hope, as well as in Arabia. It likes grassland, rocky regions, or light forests, especially near streams, but is not found in heavy forests or at very high altitudes. It grows to a length of 5 feet and is massive and bloated in appearance. The head is flat, and the nostrils are on top of the snout. The skin is deep golden yellow to orange brown, with regular chevron-shaped brown or black bars pointing backward, with a large dark blotch edged with light yellow on the crown of the head. It often lives around houses in order to feed on the rats and mice. When disturbed, it suddenly hisses by exhaling its breath. It is not aggressive, but when danger threatens it can strike with lightninglike speed. It is extremely prolific, a female laying up to 72 eggs at a time. Sometimes the young are born before the egg is laid, more usually it occurs immediately after the fully developed egg is deposited. The bite is extremely dangerous, but the venom is slow to act, compared to cobra poison. In cases of viper poisoning the administration of an alcoholic drink even in small quantities is absolutely fatal. Cattle when grazing often get struck, and in the absence of an injection of the proper serum rapidly succumb. Another closely related snake, the Cape puff adder ( $B$. inomata), is restricted to the Cape regions. 


\section{The rhinoceros viper}

With a pair of horns jutting from its nose, its swollen, wicked-looking head, and its stout, ponderous body covered with rosy, purple, blue, yellow, or brown colors-brightest after the skin is shed-the rhinoceros viper (Bitis nasicornis, pl. 12, fig. 1) is a most astonishing creature. One would expect that these bright hues would make the snake very conspicuous, but on the contrary they render the serpent almost invisible in the swampy regions near streams, especially when its rough scales are caked with mud. Another common name, the river jack, is derived from its partially aquatic habits. It does not seem to grow longer than 4 feet. It is peculiarly placid and inoffensive in disposition, and is said to be most reluctant to bite, although the venom may be even more toxic than that of the following species. Its food habits are not known, although presumably from its aquatic habits it may add frogs, toads, and even fishes to the usual viperine diet of rodents. It is practically confined to the rain forest, including Liberia, the Gold Coast, Togo, Nigeria, Cameroon, Portuguese Guinea, Belgian Congo, Uganda, and part of Kenya Colony.

\section{The gaboon viper}

This malevolent-looking serpent (Bitis gabonica, pl. 12, fig. 2) is very highly poisonous, and its prey is killed almost instantly by injections driven deeply with the long fangs. Its venom is particularly deadly as far as mankind is concerned, for it contains both the normal viperine haemotoxic elements and powerful neurotoxic properties usually found only in cobra venom. It lives in heavy forests in West Africa. It is known to reach a length of 5 feet 8 inches, the fangs of such a monster measuring nearly 2 inches, and the body nearly 15 inches around. It is not usually aggressive and has the habit of deflating its body in a loud hiss. It feeds upon small mammals and birds, toads and frogs. There is a series of oblong buff markings on the back, surrounded by rich brown and purplish spots; the sides have triangular brown or purple spots, the points directed upward. The ground color of the skin is pinkish brown. The eyes are silvery. Sometimes there is a blunt or a forked horn on the nose.

\section{The horned adders}

Two of these small snakes (Bitis cornuta, B. caudalis) have one or more hornlike scales over the eye, hence their common name. They are no more than $1 \frac{1}{2}$ feet in length, but are extremely dangerous in spite of their small size, owing to their habit of burying themselves in the sand with only the head above, where they lie for hours watching for lizards and 
other small creatures on which they feed. They bite instantly at the bare feet of any native who may come near them, for they are practically invisible as they lie hidden. They occur only in the sandy areas of the southern part of Africa.

The berg adder ( $B$. atropos) as its name indicates, lives upon the mountain ranges throughout the whole of South Africa. It devours lizards and the young of ground-nesting birds, as well as insect larvae, and mice and rats. It is highly venomous.

\section{The sand vipers}

The Sahara Desert harbors two species of sand vipers (Aspis cornuta, A. vipera, pl. 13, fig. 1) admirably adapted for life in dry desert sand. The ribs are capable of flattening the body, and there is a muscular arrangement that permits the snake to use the sharp edges of its flattened body to shovel sand over its back by a sort of wavy motion that permits the body of the snake to sink quickly below the surface, where it lies with the top of its head protruding. The eyes are on top of the head, and are the same color as the sand, so the snake cannot readily be seen. Aspis cornuta has a small, sharp spine over each eye, which is lacking in $A$. vipera. While these two species resemble the horned adders of South Africa in habits, their ranges are widely separated, and there are several structural features to distinguish them.

The carpet viper (Echis carinatus) living in sandy regions of Africa north of the Equator likewise occurs in Arabia, Persia, and India, as mentioned above (see p. 21), unlike the other poisonous snakes of Africa, which are confined to their own continent. It sometimes burrows to hide, but is not confined to arid plains, since it is found on grassy, sandy plains or even in sandy forest land. It is less than a yard in length, marked with square brown spots on a cream or reddish ground color. It is nocturnal by habit and largely insectivorous.

\section{The Cobras and Their Allies}

Except for Australia, there are more different members of this family (Elapidae) in Africa than in any other part of the world. They are terrestrial, aquatic, or arboreal, and some kind is found in almost every region of Africa except the snow-clad mountain tops and sterile deserts. The traveler has to fear not only the biting at close range, but the "spitting" of venom from a short distance by some species. These will be considered first. 
The ringhals or spitting snake

This snake (Haemachates haemachatus, pl. 13, fig. 2) differs from other cobras in having keeled scales, so that the skin is not so shiny and sleek as that of its relatives. It is the smallest of the cobras, averaging about 4 feet in length. It is black with irregular cross bars of brown above, and the throat often has one or two white or yellowish bands, hence its Dutch name of ringhals (= ring neck). The ringhals is aggressive when disturbed and will advance on a man or even pursue him for a considerable distance. The danger from this snake comes when people stoop toward the ground or rock pile where an alert ringhals may be lying, as the venom is ejected in two streams from the fangs, accompanied by the expulsion of air from the lungs, so that it is sprayed in a fine shower for several feet. The snake aims its venom at the eyes of its victim. The entry of venom into the eyes causes intense pain, followed by inflammation and partial or total blindness. The eyes should be promptly and efficiently treated by washing at once with water and boric acid. The poison is not harmful when it falls on the unbroken skin. Eyeglasses or goggles afford adequate protection to the eyes against the spray of venom. Owing to its small size, the ringhals can throw its venom only about 6 feet. The bite of the ringhals is as deadly as that of any other cobra. Unlike most cobras, this snake produces its young alive, in litters of from 24 to 60. It is common throughout South Africa.

\section{The spitting or black-necked cobra}

The black-necked cobra (Naja nigricollis) also sprays its venom. Larger in size, it is even more formidable than the ringhals. It has a much wider range than the ringhals, being found from upper Egypt to Angola and the Transvaal, and is very common in some regions. It rears and "spits" upon slight provocation, and the venom is effective at distances up to 12 feet. The snake is 7 feet long when fully grown, and since it rears its head to a height of 3 feet from the ground, its attack is unexpected and overpowering. The effect of the venom on the eyes of the victim is as disastrous as that of the ringhals. It is probable that if nothing were done to dilute or wash away the poison from the absorbent membranes of the eyes, blindness would result. Not enough of the poison seems to be absorbed to cause death, however. This snake may be lustrous black, olive, brown, or salmon pink in color. The black variety may show a pair of large crimson blotches under the hood when this is spread. The lighter-colored specimens have a black band across the throat, giving the snake its common name. 
The black cobra

This serpent (Naja melanoleuca) is slightly larger and heavier than the spitting cobra, and looks somewhat like it. It does not spit venom, but is quick to become angered and will rush to attack whoever comes near. It is confined to tropical Africa. The shiny texture of its skin distinguishes it from the dark variety of the spitting cobra.

\section{The Egyptian cobra or asp}

This snake (Naja haje, pl. 14, fig. 1) is the most widely distributed of the African cobras, being found in the whole of North Africa except in the coastal area of Algeria. It is especially numerous in countries bordering the Sahara, and extends through East Africa all the way to Natal. Its color is a dull brown, blending well with the hot, dry sand through which it prowls in search of rats and mice. It takes freely to water, where it devours frogs and toads. It grows to 6 feet in length. By disposition it is very irritable, hissing and striking repeatedly at the slightest disturbance.

\section{The Cape cobra}

The bad temper and ferocity of this snake (Naja flava) is well recognized in the south of Africa where it occurs from Cape Colony to southern Tanganyika. It is found with several different colorations, individuals being yellowish, reddish, brown, or black. It frequently climbs trees in search of young birds and eggs.

Several other species of cobras inhabit rather restricted areas in West Africa or Angola, some of them nearly "hoodless" but otherwise unmistakably cobras.

\section{The water cobra}

These aquatic cobras (Boulengerina, pl. 14, fig. 2) live in Cameroon, the French and Belgian Congos, and in Lake Tanganyika. In the last-named place they stay around rocks, on top of which they bask in the early morning sun before taking to the lake. They grow to around 8 feet in length. Their degree of toxicity is not definitely known, but out of the water they are apparently not nearly so aggressive as the true cobras. Most of them have a black bar behind the head, followed by a number of black, usually light-centered spots. They probably seldom go far from water. 


\section{The mambas}

These deadly snakes (Dendraspis, pl. 15, fig. 1) are set apart from the other poisonous snakes of Africa by their extreme slenderness. This makes them admirably adapted for an arboreal existence, and their green or blackish coloration makes them almost indistinguishable among the stems of climbing vines. The head is narrow and the eyes large. The mamba looks rather like the harmless tree snakes of similar build found in the Tropics of both hemispheres. When it opens its mouth, however, there is no mistaking its poisonous character, for the large fangs are situated at the very front of the mouth. One species may be as long as 12 feet, a length unmatched anywhere among elapine snakes except by the king cobra of southern Asia. In striking, it takes advantage of its length by doubling back its neck laterally and then lunging forward nearly half of the body length. Birds and small rodents comprise its food; in searching for the latter it often takes to the ground and even enters native huts. There are several species of mambas now recognized, and in distribution they pretty well cover the southern part of Africa north to Abyssinia and the Niger. Mambas are said to be very sociable, several males and females being frequently found inhabiting the same hollow in the trunk of a tree, a crevice among boulders, or a hole in a bank, and often sharing their retreat with a black-necked cobra. The eggs are laid in dense vegetation, and the young snakes take to the trees as soon as they are hatched.

\section{The boomslang}

The ReAR-FANGed SNAKeS

The boomslang (Dispholidus typus) belongs to the rear-fanged group of the family Colubridae, and in build is like one of our racers. The color varies greatly, from green through all shades of brown to black, the scales of the lighter-colored individuals often being edged with black. An adult may measure over 6 feet in length. Its name in Dutch means "tree snake," and the trees are its natural environment. In sparsely wooded country it takes to the ground to hunt frogs, lizards, ground birds, caterpillars, and various insect larvae. The eggs are laid in decaying vegetation on the ground. When biting, the boomslang does not readily let go when once it has seized its prey. Unless its grip is complete, the fangs do not penetrate the flesh, since they are set halfway back in the upper jaw under the eyes, and are comparatively small. Fortunately this snake is very timid and will make off into the bushes at the slightest alarm. When it bites, however, its venom is very active, and the results may be fatal to human beings, as they undoubtedly have been fatal to dogs, oxen, and other farm animals. 
AUSTRALIA, NEW GUINEA, AND THE SOUTH PACIFIC ISLANDS

Aside from the sea snakes of the family Hydridae which live in the waters of the northern coasts, Australia has but one family of poisonous snakes, the Elapidae. This family has an extremely large representation there, however, as 14 genera and 80 species are known. While a number of these are not considered dangerous to man owing to their small size, short fangs, and timid dispositions, the larger kinds are outstanding for their abundance, insolence, and high toxicity. There is a great range in the toxic power among the really dangerous species. While the action of the poison is more largely neurotoxic-as in other members of the Elapidae throughout the world-there are some haemolytic effects as well. Most of the cases of snake bite in Australia could be avoided by the use of boots and leggings, as the snakes do not rear very far from the ground in attacking, and few are arboreal, hence the feet and legs of a pedestrian are in most danger of being struck by the fangs.

New Guinea has, in addition to a liberal population of sea snakes, several representatives of some of the deadly kinds found in Australia.

There are no poisonous snakes in New Zealand. The Hawaiian Islands are likewise devoid of them, as well as most of the scattered islands of the South Pacific. One genus of the family Elapidae, Ogmodon, is found in the Fiji Islands. Several of the same family occur in the Solomon Islands, while some of the sea snakes live in the surrounding waters.

\section{The black snake}

This snake (Pseudechis porphyriacus, pl. 15, fig. 2), most abundant of the larger poisonous kinds of Australia, grows to a length of 6 to 7 feet. The smooth scales are satiny blue black above, while below they are brilliant scarlet edged" with black. The neck is slightly extensible so that a "hood" about half as broad as that of a cobra can be formed. When about to attack, it does not rear like the cobra, but instead raises the head only a few inches from the ground. It will not attack man unless trodden upon or cut off from means of escape. It prefers marshy places or streams, and dives and swims well. It can stay under water for a long time, and from its habit of lying still at the bottom of lakes and streams it is dangerous to bathers. Its food consists of frogs, lizards, and small mammals and birds. The young are born alive in March, up to two dozen to a litter. During the winter the black snake hibernates in holes in the ground. It is found throughout Australia, except in the north, but does not occus in Tasmania. Its bite is said to be less dangerous than that of the other large Australian snakes, owing to the lower toxicity of its venom. 
Several other snakes of the genus Pseudechis live in Australia. One of these, inhabiting central Queensland, grows to be 9 feet long, with proportionately large fangs and poison glands.

A still larger snake, the giant brown snake (Oxyuranus scutellatus), belongs to a closely related genus. It is restricted to Cape York Peninsula. It is known to reach a length of over 9 feet.

\section{The copperhead snake}

While a reddish brown or dark brown color usually characterizes this snake (Denisonia superba, pl. 16, fig. 1), occasionally a bright red or black individual is found. The head is usually of a coppery tone, especially so in the young ones. It is a stouter-bodied creature than the black snake, and does not grow quite so large, as 6-foot specimens are considered uncommonly large. When angry, it is said to rear a few inches from the ground, with the neck slightly curved, as the cobra does. Like the black snake, it frequents swamps and feeds on lizards and frogs. It is found in southeastern Australia and in Tasmania.

There are about two dozen other closely related species belonging to this genus in Australia, some of them being no more than 15 inches long and with relatively weak venom.

\section{The brown snake}

The larger members of the genus Demansia are considered highly dangerous, especially the brown snake (D.textilis, pl. 16, fig. 2), which is usually 5 to 6 feet long, and widely distributed all over Australia. It is light yellow to brown or gray above and white below. The young, hatched from eggs, are ringed during their first year. This snake has a small head, but its bite is extremely serious, owing to its highly toxictrenom. The snake is all the more dangerous as there is nothing in its appearance or behavior to excite fear, since it resembles one of our whipsnakes. There are about a dozen species of this genus, and several of them are called whipsnakes, owing to their slender build.

Related forms of this dangerous snake occur in New Guinea as well.

\section{The tiger snake}

The dark bands on a tawny ground suggest the name of this, the most savage and dangerous of Australian reptiles (pl. 17, fig. 1). Sometimes the ground color is so dark that the bands are indistinct. The venom is of such extremely high toxicity that it is not equaled by that of any other known snake. It seems to cause more fatalities in Australia than all the 


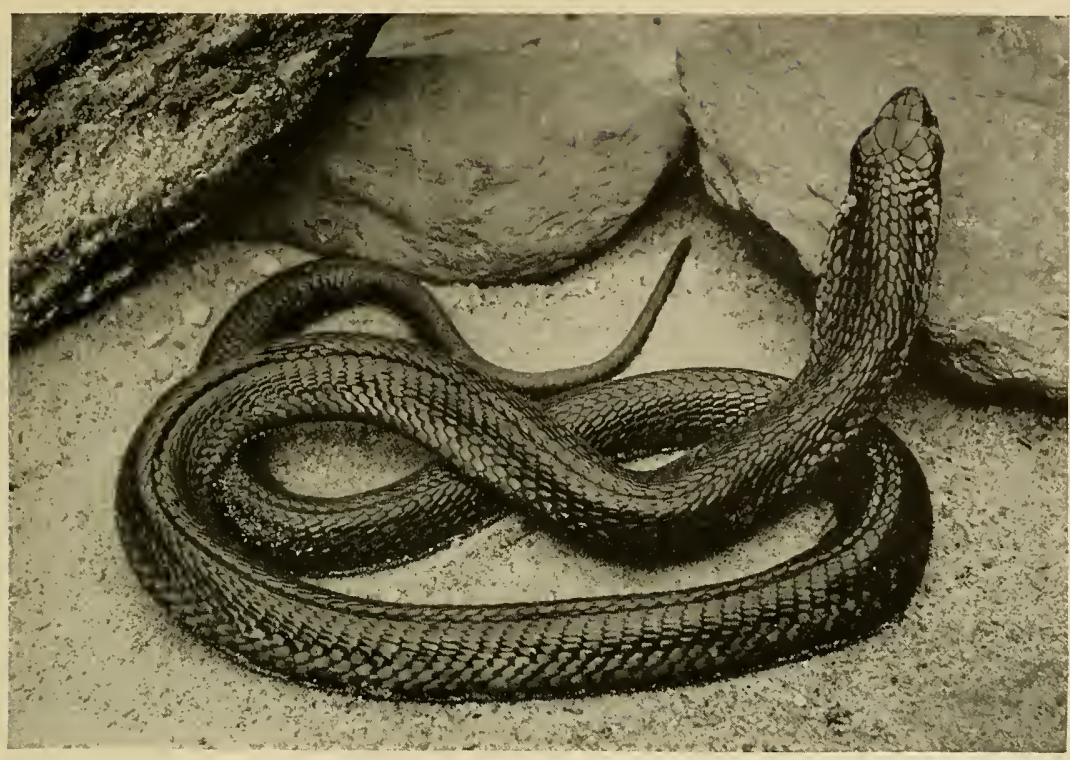

Courtesy New York Zoological Society

1. Egyptian cobra (Naja haje), also called asp. Color: brown, sometimes with faint darker markings. Length: 6 feet. Range: northern and eastern Africa from Morocco to Natal. Extremely poisonous; irritable and aggressive.

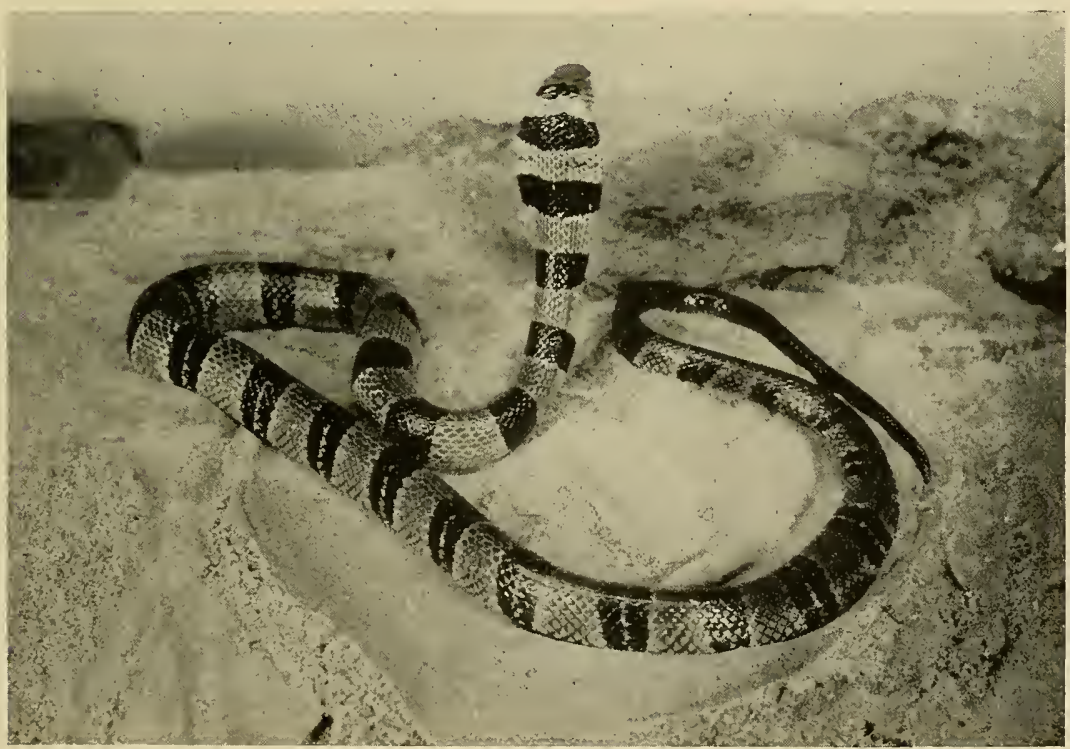

Courtesy New York Zoological Society

2. Water cobra (Boulengerina stormsi). Color: light brown with a series of black, light-centered bands or spots on the body. Length: 8 feet. Range: lakes and rivers in Cameroon, the French and Belgian Congos, and Lake Tanganyika. Degree of toxicity unknown; aquatic; not aggressive out of water. 


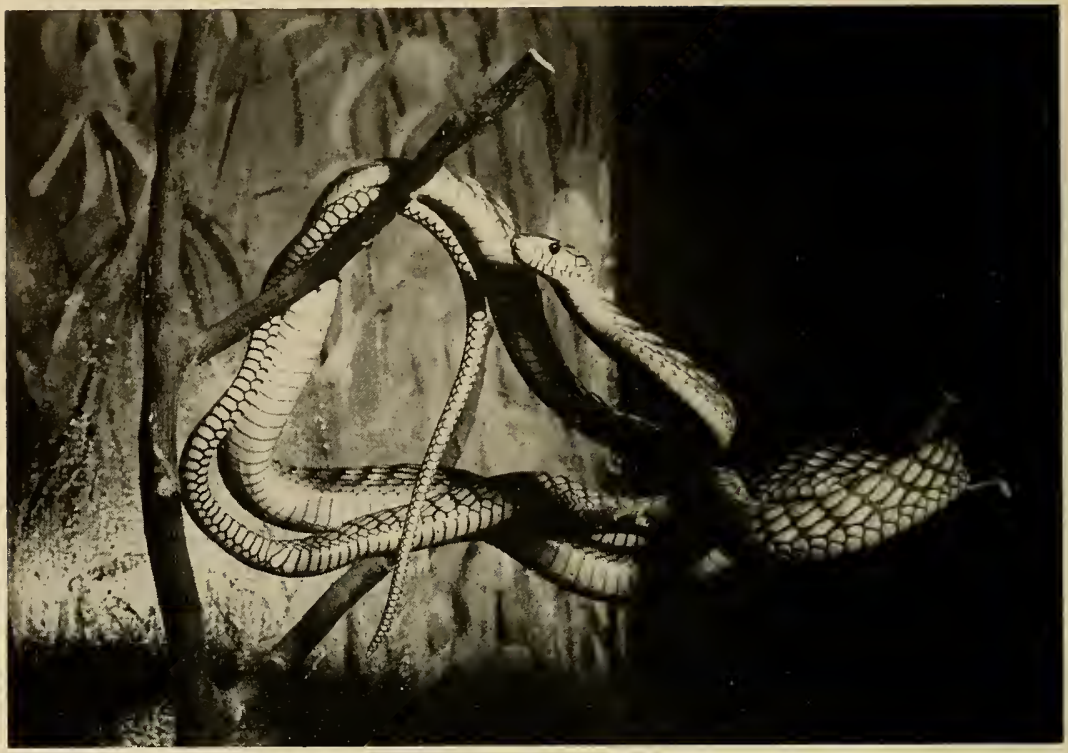

Courtesy New York Zoological Society

1. Green mamba (Dendraspis viridis). Color: green or dark olive, uniform or each scale brown at the end; lips yellowish, outlined with black. Length: $7 \frac{1}{2}$ feet. (Other kinds are much longer.) Range: West Africa from the Senegal to the Niger. Extremely poisonous.

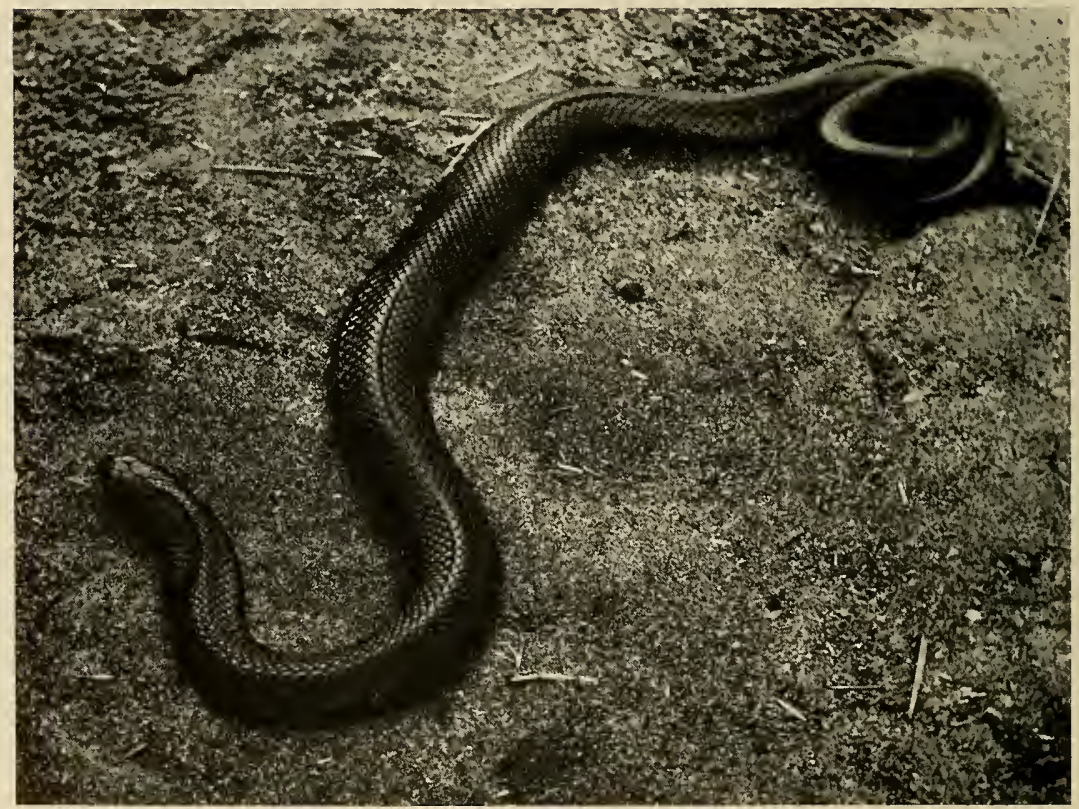

Courtesy Bulletin of the Antivenin Institute

2. Australian black snake (Psezdechis porphyriacus). Color: above blue black; beneath scarlet, the scales often edged with black. Length: 6 to 7 feet. Range: Australia, except the northern part. 


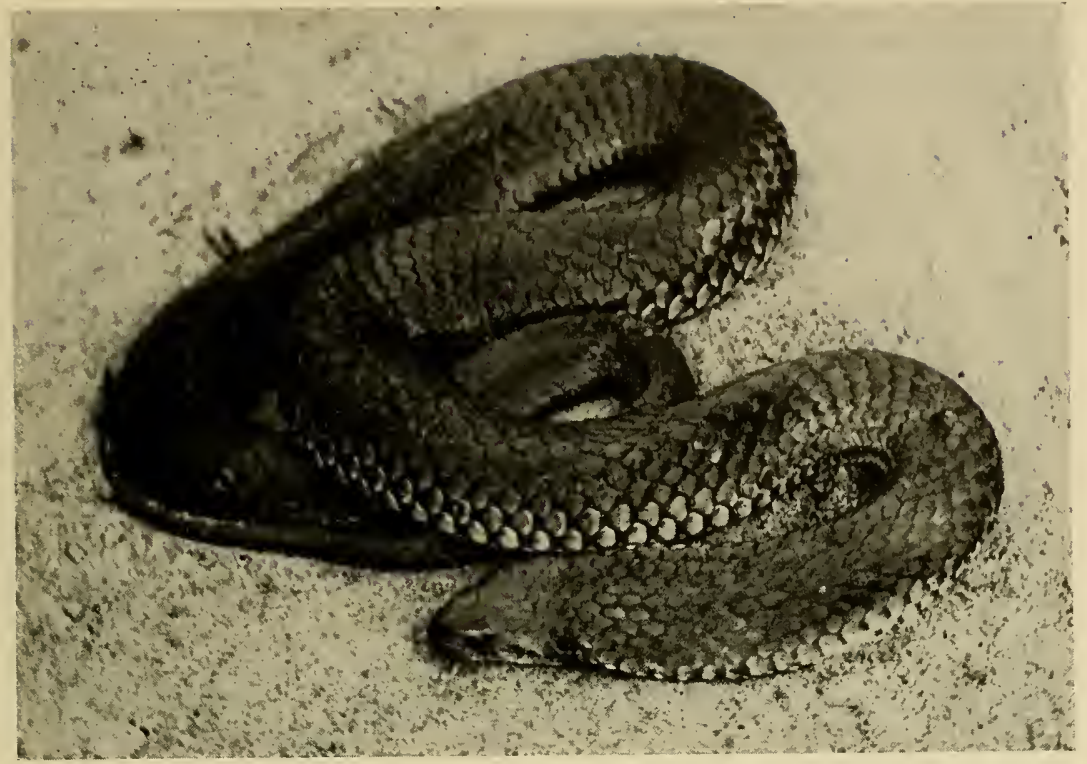

Courtesy Bulletin of the Antivenin Institute

1. Australian copperhead (Denisonia superba). Color: brown to black above, the head usually coppery. Length: up to 6 feet. Range: southeastern Australia and Tasmania. Dangerously poisonous; not aggressive.

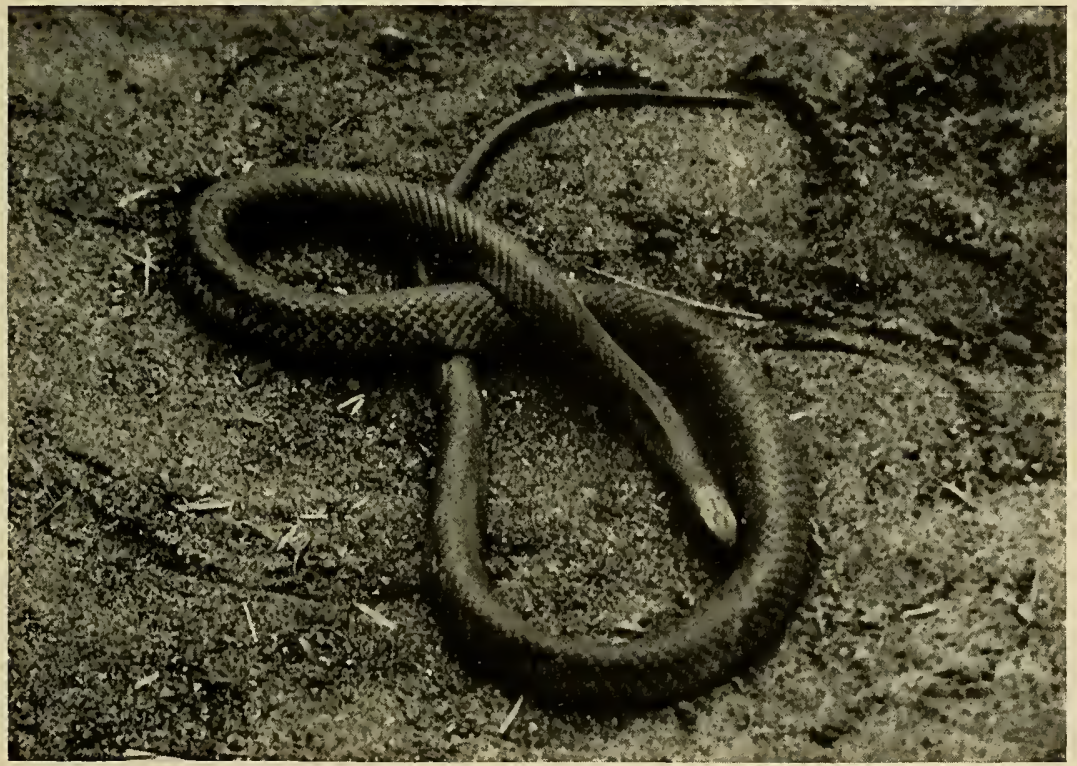

Courtesy Bulletin of the Antivenin Institute

2. Brown snake (Demansia textilis). Color: light brown or gray above, white below; young specimens ringed with black. Length: 6 feet. Range: widely distributed throughout Australia. Extremely poisonous; not aggressive. 


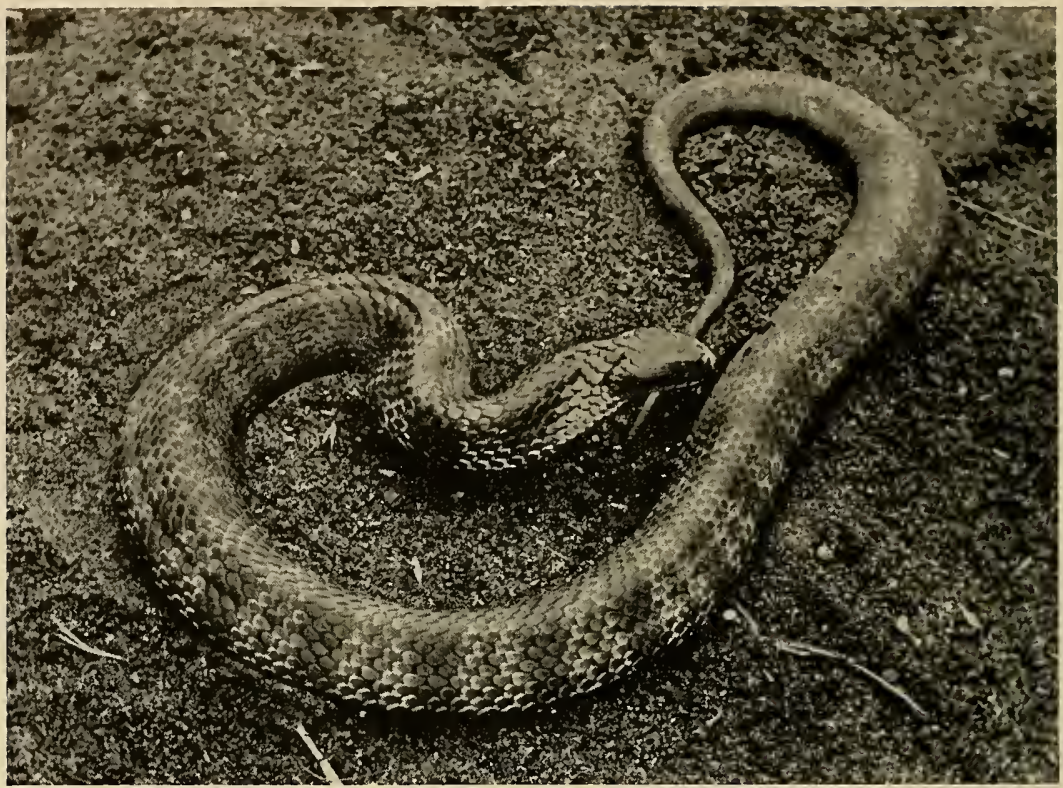

Courtesy Bulletin of the Antivenin Institute

1. Tiger snake (Notechis scutatus). Color: green, gray, orange or brown, with dark bands. Length: over 5 feet. Range: southern half of Australia. Extremely poisonous; very aggressive.

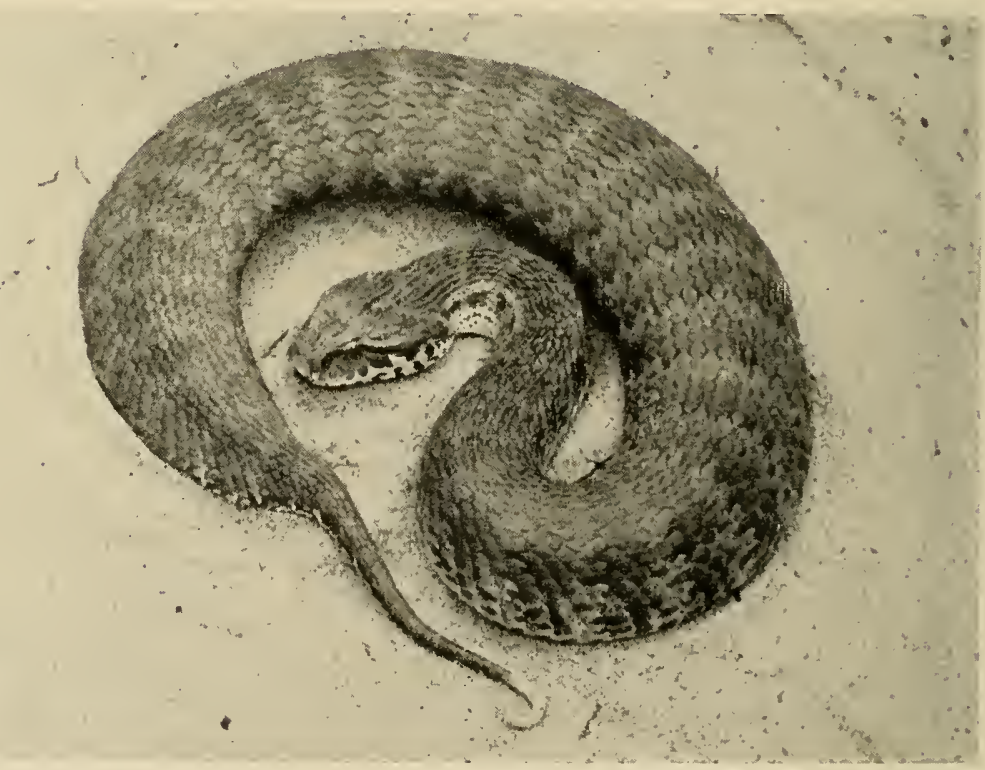

Courtesy Bulletin of the Antivenin Institute

2. Death adder (Acantbophis antarcticus). Color: brownish or gray, with dark bands which are most apparent in the young. Length: 3 feet. Range: dry parts of Australia, except Victoria. Extremely poisonous. 
other poisonous snakes of that country put together. The tiger snake (Notechis scutatus), when disturbed, becomes furious, spreads out the neck to twice its usual width and rushes toward its enemy. It resents being interfered with by other snakes and is said to be more than a match for the black snake. A man bitten by this snake may die within an hour if no treatment is given, and a dog in less than 20 minutes. The tiger snake is between 5 and 6 feet in length when full-grown, and its body is rather stout. It is extremely prolific, producing 50 or more young in a litter. Its food consists mainly of lizards. It likes dry country, hence its, range is extensive both in Australia and Tasmania.

\section{The death adder}

A short, thick, clumsy body not more than 3 feet long, and resembling that of a viperine snake far more than its own relatives just enumerated, characterizes the death adder (Acanthophis antarcticus, pl. 17, fig. 2). In color it resembles the ground it lies on, so that it may be gray, brown, pink, or brick red, depending on the sandstone of the region in which a particular individual may live. In younger specimens, bands of darker shade cross the body; these may disappear with age. It is found in sandy localities over most of Australia except in southern Victoria, as well as in New Guinea and the Moluccas, thus having the widest range of any Australian poisonous snake. The young are born alive, about a dozen at a time. It has very rough scales, even on the head, and there is a spine on the tail, probably to assist in locomotion through the sand. Its large head bears fangs that are no longer than those of the tiger snake, and its venom is so active that it is reckoned as highly dangerous. It is not so quick to strike as the tiger snake, but as it is likely to be stepped on, it is a constant menace.

The broadheaded snake (genus Hoplocephalus), the black and white ringed snake (genus Furina), the red-bellied snake (genus Pseudelaps), and their allies are not considered very dangerous to man, either because of their small size, their relatively weak venom, or their short fangs, and therefore will not be considered here. The status of the poison of some snakes, such as Micropechis ikabekae of New Guinea and the Solomons, is not yet established.

\section{The Sea SNakes}

This family (Hydridae) is the only other family of poisonous snakes found in Australia besides the Elapidae just discussed. It would be more proper to say "in the waters off the coasts," for these snakes are never 
found inland. Twenty-seven species have been listed from the waters bathing the northern shores of Australia; these belong to 12 different genera. Since this group has been discussed under the section on "Asia and Malaya," it will not be further touched upon here.

\section{SELECTED BIBLIOGRAPHY}

Antivenin Institute of America.

1927-1931. Bull., vols. 1-5. Glenolden, Pa.

BOULENGER, GeORGE A.

1890. The fauna of British India including Ceylon and Burma. Taylor and Francis, London.

1912. A vertebrate fauna of the Malay Peninsula. Reptilia and Batrachia. Taylor and Francis, London.

1913. The snakes of Europe. Methuen and Co., London.

De Rouij, Nelly.

1917. Reptiles of the Indo-Australian Archipelago. II. Ophidia. E. J. Brill, Ltd., London.

DitMARS, RAYMOND L.

1907. The reptile book. Doubleday, Page and Co.

1930. The poisonous serpents of the New World. Bull. New York Zool. Soc., vol. 33, No. 3, May-June.

1934. Snakes of the world. Macmillan Co.

Fitzsimons, F. W.

1912. The snakes of South America. Longman, Green and Co., London.

KINGHORN, J. R.

1929. The snakes of Australia. Angus and Robertson, Ltd., Sydney, New South Wales.

Pitman, Charles R. S.

1938. A guide to the snakes of Uganda. Kampala.

Pope, Clifford H.

1937. Snakes alive and how they live. Viking Press, New York.

Smith, MaLColm.

1926. Monograph of the sea-snakes (Hydrophiidae). British Mus., London. STE JNEGER, LEONHARD.

1895. The poisonous snakes of North America. Ann. Rep. U. S. Nat. Mus. for 1893, pp. 337-487.

WaLL, FRANK.

1921. The snakes of Ceylon. H. R. Cottle, Ceylen. 


\section{APPENDIX}

\section{FIRST-AID TREATMENT}

While it is not within the scope of this paper to give any medical advice as to the treatment of cases of snake bite, it is desirable to republish the first-aid directions contained in a leaflet issued by the makers of standard antivenin serum. They say:

\section{IN CASE OF BITE}

Snake bite should be treated immediately. If a physician is not available, the following first-aid measures should be employed:

\section{FIRST AID}

Apply constricting band above bite just tight enough to prevent absorption and not interfere entirely with flow of blood. A cold, numb limb means constriction is too tight and should be loosened.

Make deep X-shaped cuts $\frac{1}{2}$ inch long through skin at points where fangs entered skin. Let the blood flow from these cuts. Make additional cuts at edge of swollen area. Help flow of blood and serum from these cuts by suction. Make suction for 15 or 20 minutes every hour for several hours. In interval between suction treatment, cover with cloths wet with strong solution of table salt or epsom salt in water.

Don't cauterize the wounds or apply potassium permanganate.

Don't run or exercise. Don't take any alcoholic stimulants.

\section{ASSOCIATED TREATMENT}

Of general measures apart from antivenin, sedatives, such as morphine or aspirin, or small doses of a barbiturate may be given to relieve pain and nervous. ness. For collapse, strychnine, aromatic spirits of ammonia or other general stimu. lants are of some value. In all severely poisoned persons, great relief is likely to be experienced from the infusion of a large amount of physiological saline, or still better, transfusion of blood, the effects of which may be life saving in borderline cases.

\section{ANTIVENIN AND ITS PREPARATION}

Antivenin, a serum used to combat the deadly effects of the bites of poisonous snakes, is prepared by medical institutions in many countries. In the United States, the Mulford Biological Laboratories at Glenolden, $\mathrm{Pa}$., furnish a serum for the bites of all the poisonous snakes found in the United States. Before using a particular serum, it is necessary to know to what group the snake belonged which bit the victim, for coral snake 
serum is not effective on pit viper poisoning, since the poisons of the coral snakes and pit vipers are essentially different. A serum made from the venom of any species of rattlesnake is more or less effective in treating bites by other kinds of rattlesnakes, however.

In preparing serum, the venom is collected by "milking" the glands of a live poisonous snake. This venom is then dried, diluted considerably, and injected subcutaneously into horses. The dose is repeated every few days, being slightly increased at each injection. The horses eventually reach a state of protection in which they will bear very large doses of venom, several hundred times as much as would kill a normal horse. When the horses reach this stage, they are bled. The serum is separated from the red blood cells and concentrated by a special process which removes a large proportion of the proteins, but leaves the antivenin in the final product. This concentrated serum is the antivenin of commerce.

A famous laboratory for making antivenin for the bites of neotropical poisonous snakes is the Instituto Butantan at São Paulo, Brazil. In exchange for live snakes from which to obtain fresh venom, which are sent in by planters and farmers all over Brazil, the institute furnishes fresh antivenin to use in the many cases of snakebite occurring among the laborers clearing ground for new plantations. The death rate from snakebite in Brazil was estimated to be about 3,000 a year before the establishment of the institute. In 1930, however, after careful tabulation, the total appeared to be well under 100 .

There is a research plant at Tela, Honduras, where the poisons of the pit vipers from the banana and coffee areas of Central America are extracted. These poisons are sent to the United States to be used in producing the antivenin, which is then shipped back ready for injection.

In Australia, the Commonwealth Serum Laboratories at Melbourne manufacture antivenin for the bites of the tiger snake and death adder, the two most deadly snakes of that region.

In the French colonies, various branches of the Pasteur Institute provide serums for different kinds of local poisonous snakes. The BurroughsWelcome products, of English manufacture, are available in India and Egypt and other areas of British influence.

A polyvalent serum, made from the poisons of several groups of poisonous snakes, is useful when the kind of snake that made the bite is unknown.

\section{DIRECTIONS FOR MAKING SCIENTIFIC COLLECTIONS}

In little-explored regions there is always the incentive of discovering unknown species, which would be of great scientific value if they could be 
collected and preserved for the United States National Museum in Washington, D. C. It is relatively easy to preserve snakes, lizards, frogs, and toads. All that is necessary after killing them is to make a short incision with a penknife on the ventral surface into the stomach and intestines, then they can be dropped into a solution of 1 part formaldehyde and 10 parts water and left for 2 or 3 days. They should then be changed into a fresh solution of the same strength. When they are to be packed for shipment, an empty gasoline tin should be lined with paper or straw to prevent the rust from discoloring the skins of the preserved specimens. The specimens themselves should be loosely wrapped in cheesecloth dampened with formaldehyde, with the place of collection, the date collected, and the name of the collector very plainly written with soft black pencil on heavy paper. This information is absolutely necessary, for without it the specimens are valueless. The gasoline tin may then be soldered shut, and the specimens will keep for several months without more attention. Those interested in natural history will find it a pleasant occupation for spare time to make such collections, and the collections will be assured of prompt study and identification upon their arrival at the United States National Museum. 




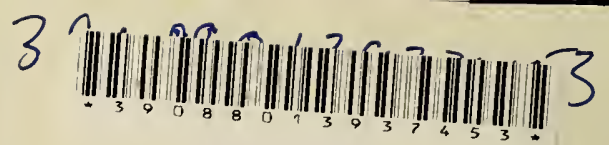

